\title{
Roles of luteal and allantoic function in late embryonic/early fetal pregnancy failures in cattle
}

Justin D. Rhinehart

West Virginia University

Follow this and additional works at: https://researchrepository.wvu.edu/etd

\section{Recommended Citation}

Rhinehart, Justin D., "Roles of luteal and allantoic function in late embryonic/early fetal pregnancy failures in cattle" (2007). Graduate Theses, Dissertations, and Problem Reports. 2573.

https://researchrepository.wvu.edu/etd/2573

This Dissertation is protected by copyright and/or related rights. It has been brought to you by the The Research Repository @ WVU with permission from the rights-holder(s). You are free to use this Dissertation in any way that is permitted by the copyright and related rights legislation that applies to your use. For other uses you must obtain permission from the rights-holder(s) directly, unless additional rights are indicated by a Creative Commons license in the record and/ or on the work itself. This Dissertation has been accepted for inclusion in WVU Graduate Theses, Dissertations, and Problem Reports collection by an authorized administrator of The Research Repository @ WVU.

For more information, please contact researchrepository@mail.wvu.edu. 


\title{
Roles of Luteal and Allantoic Function in Late Embryonic / Early Fetal Pregnancy Failures in Cattle
}

\author{
Justin D. Rhinehart \\ Dissertation submitted to the \\ Davis College of Agriculture, Forestry, and Consumer Sciences \\ at West Virginia University \\ in partial fulfillment of the requirements \\ for the degree of \\ Doctor of Philosophy \\ in \\ Reproductive Physiology \\ E. Keith Inskeep, Ph.D., Chair \\ Robert A. Dailey, Ph.D. \\ Stanley Hileman, Ph.D. \\ Jorge A. Flores, Ph.D. \\ George E. Seidel, Ph.D. \\ Michael W. Vernon, Ph.D., HCLD, ELD \\ Faculty of Reproductive Physiology \\ Morgantown, West Virginia \\ 2007
}

Keywords: pregnancy failure, embryonic mortality, fetal

mortality, progesterone, dairy cattle 


\section{ABSTRACT \\ Roles of Luteal and Allantoic Function in Late Embryonic / Early Fetal Pregnancy Failures in Cattle}

\section{Justin D. Rhinehart}

Pregnancy failures during placentation in lactating dairy cows have been associated with low concentrations of peripheral serum progesterone $\left(\mathrm{P}_{4}\right)$ and poor development of the chorioallantoic membranes. Experiment I was done to determine if pregnant cows with high or low concentrations of serum $\mathrm{P}_{4}$ differed in luteal production of $\mathrm{P}_{4}$ and/or clearance of injected $\mathrm{P}_{4}$. Luteal tissue was removed from pregnant cows with $\geq 4.0$ $\mathrm{ng} / \mathrm{mL}$ (High) or $\leq 2.5 \mathrm{ng} / \mathrm{mL}$ (Low) serum $\mathrm{P}_{4}$ during d 28 to 34 post-insemination. Luteal tissue was assayed for $\mathrm{P}_{4}$ by radioimmunoassay and for expression of mRNA for preproendothelins 1 and 3, endothelin converting enzyme, endothelin receptors $A$ and $B$, cyclooxygenase-2, aldoketoreductase 1B5, 15-hydroxyprostaglandin dehydrogenase, and prostaglandin E synthase by real-time RT-PCR. Dispersed luteal cells were incubated for $2 \mathrm{~h}$ with bovine luteinizing hormone (bLH) or arachidonic acid (AA), increasing $\left(10^{-10}\right.$ to $10^{-7} M$ ) concentrations of endothelin-1 (ET-1), and combinations of ET-1 and bLH or AA. Neither luteal content of $\mathrm{P}_{4}$ (mean $106 \pm 12 \mu \mathrm{g}$ ) nor mRNAs for the endothelin or prostaglandin systems differed with serum $\mathrm{P}_{4}$ at lutectomy. Both basal and LH-stimulated secretion of $\mathrm{P}_{4}$ from dispersed luteal cells were inhibited $(\mathrm{P}<0.05)$ by ET-1 in a dose dependent manner. Inhibition by ET-1 was greater $(\mathrm{P}<0.05)$ for luteal cells from Low vs. High cows when incubated with AA. Both basal and AA-stimulated secretion of $\mathrm{PGF}_{2} \alpha$ by luteal cells were increased by ET-1 in a dose-dependent manner. Basal and AA-stimulated 6-keto-PGF $1 \alpha$ were decreased by ET-1 in a dose-dependent manner. To evaluate clearance of $\mathrm{P}_{4}$, cows were injected s.c. with $150 \mathrm{mg} \mathrm{P}_{4}$ every $12 \mathrm{~h}$ beginning at lutectomy. In jugular blood collected every $4 \mathrm{~h}$ until $\mathrm{h} 48$, serum $\mathrm{P}_{4}$ was maintained at lower $(\mathrm{P}<0.05)$ concentrations for Low vs. High cows. Area under the curve was less $(\mathrm{P}$ $<0.05)$ for Low $(49.6 \pm 6.2)$ vs. High $(83.6 \pm 12.5)$ cows. On the basis of these data, differences in clearance were more important than differences in luteal production to determine peripheral concentrations of $\mathrm{P}_{4}$. However, incubation with ET-1 and AA caused a greater reduction of $\mathrm{P}_{4}$ production for luteal cells from cows with Low than High serum $\mathrm{P}_{4}$. Thus, $\mathrm{CL}$ of Low cows might be more sensitive to luteolytic influences than CL of High cows. Reduced clearance of $\mathrm{P}_{4}$ might decrease late embryonic or early fetal mortality as efficiently as supplementation with exogenous progestogens. The objective of experiment II was to characterize the timing of detection of the allantois and diameter of the allantoic lumen, in dairy cows and heifers with embryos developed entirely in vivo, to determine whether these variables might be used to investigate late embryonic / early fetal loss. Reproductive tracts of dairy heifers $(n=33)$ and lactating dairy cows $(n=30)$ were examined daily, via transrectal ultrasonography (Aloka 900), beginning on d 21 post-insemination (PI). Variables included: first day of detection of the allantois, diameter of the allantoic lumen, length of the embryo at first detection of the allantois, and pregnancy retention on d 60 PI. Range and mean of first day of detection of the allantois ( $\mathrm{d} 21$ to 26 , mean $=23 \pm 0.18 \mathrm{PI}$ ) agreed with previous reports. The allantois was detected earlier $(\mathrm{P}<0.05)$ in heifers $(22.4 \pm 0.2 \mathrm{~d})$ than in cows $(23.6 \pm 0.2 \mathrm{~d})$. 
Diameter of the allantoic lumen at first detection $(4.6 \pm 0.3 \mathrm{~mm})$ did not differ with day of detection and was not affected by age of dam. In contrast, length of embryo (range 2.6 to $7.9 \mathrm{~mm})$ varied with day of first detection of the allantois $(\mathrm{P}<0.05)$, but not with age of dam. Pregnancy failure by day 60 PI did not differ with age of the dam. Differences in failure for pregnancies in which the allantois was detected earlier $(\leq \mathrm{d} 23 \mathrm{PI})$ or later $(\geq \mathrm{d}$ $24 \mathrm{PI})$ approached significance $(\mathrm{P}=0.08)$ with those detected earlier failing more frequently than those detected later. Differences in day of first ultrasonographic detection of placental membranes, between heifers and cows, might reflect differing developmental rates and, based on present data, asynchrony in development of the embryo and the placental membranes might occur in some animals. Therefore, day of detection of the allantois might be useful for predicting survival or loss of pregnancy during placentation. 


\section{TABLE OF CONTENTS}

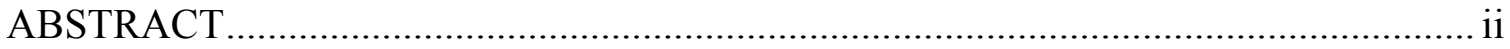

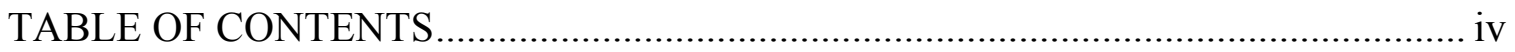

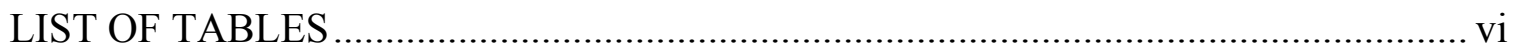

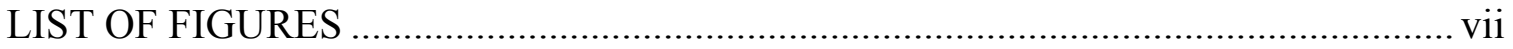

ACKNOWLEDGEMENTS................................................................................... vii

REVIEW OF LITERATURE …………………………...................................... 1

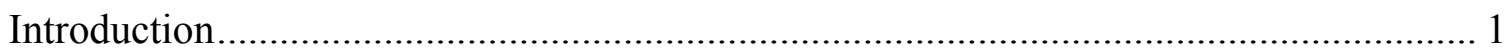

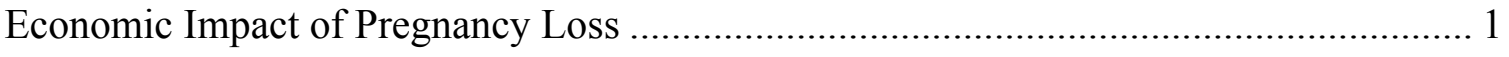

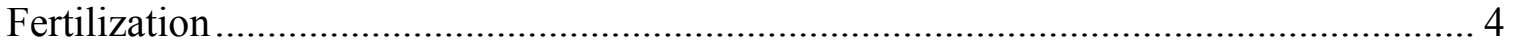

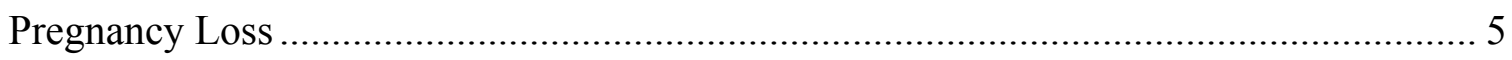

Early Embryonic Loss........................................................................................ 5

Late Embryonic / Early Fetal Loss ………………..................................................... 7

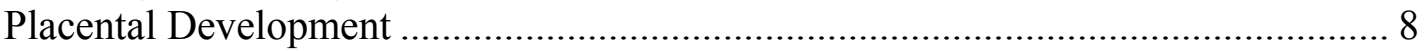

Frequency of Late Embryonic / Early Fetal Loss ……………………………........... 13

Effects of Low Progesterone on Pregnancy Loss ……………………………............. 14

Pregnancy Loss Associated with Assisted Reproductive Technology .......................... 16

Allantoic Development for IVF and SCNT embryos ........................................... 18

Ultrasonographic Evaluation of Embryonic Development................................................ 19

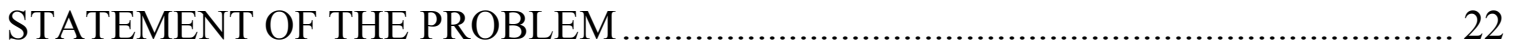

LUTEAL FUNCTION AT DAY 30 OF PREGNANCY IN RELATION TO SERUM PROGESTERONE IN DAIRY COWS AT RISK FOR LATE EMBRYONIC OR

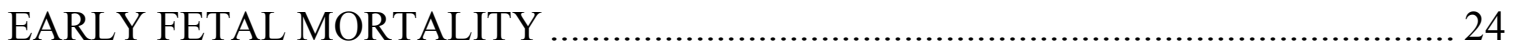

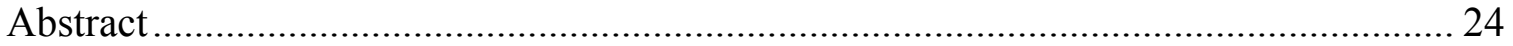

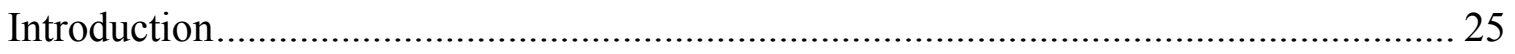

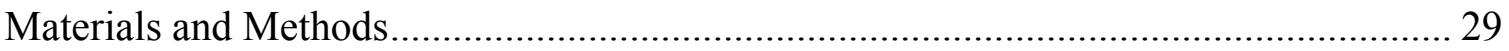

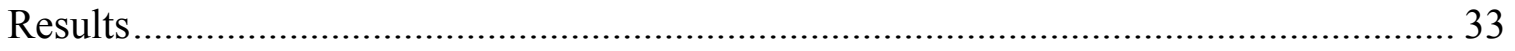

Luteal Progesterone and Gene Expression ............................................................... 33 
Luteal Cell Incubation............................................................................... 34

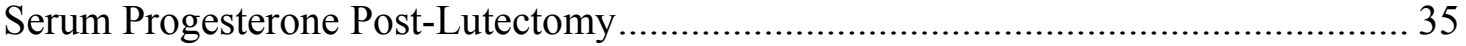

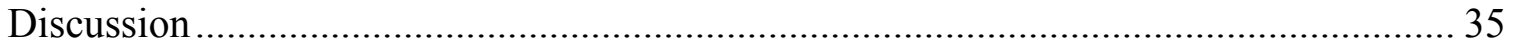

ASSOCIATION OF TIMING OF CHORIOALLANTOIC MEMBRANE

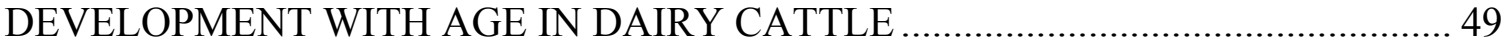

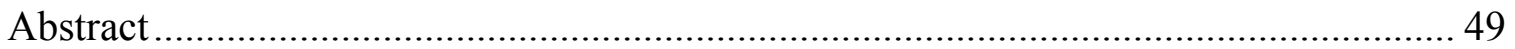

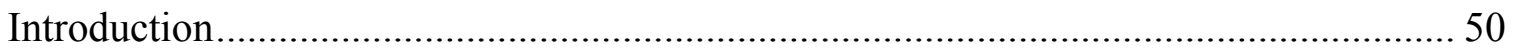

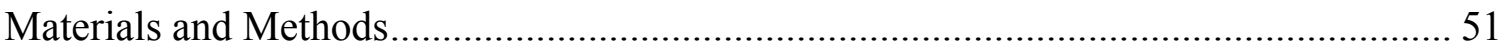

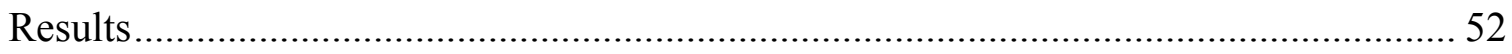

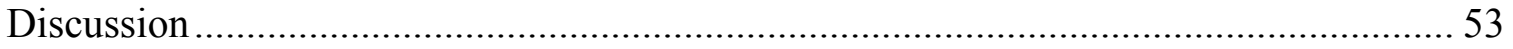

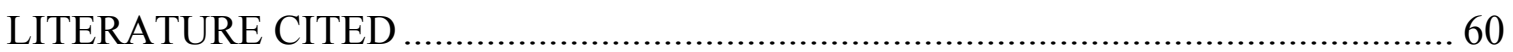




\section{LIST OF TABLES}

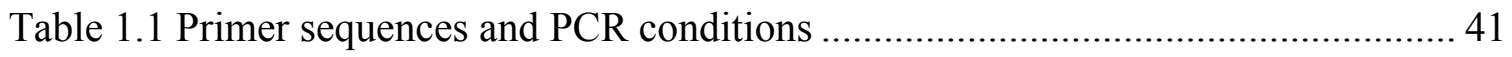

Table 2.1 Allantois Results Relative to Age of Dam..................................................... 58 


\section{LIST OF FIGURES}

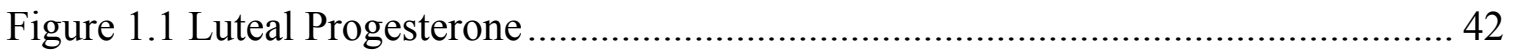

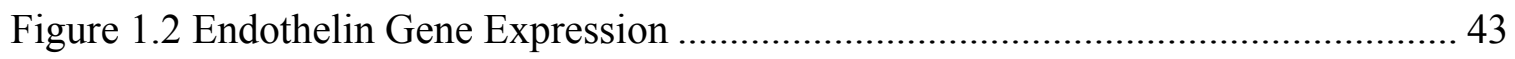

Figure 1.3 Prostaglandin Gene Expression......................................................... 44

Figure 1.4 Post Lutectomy Serum Progesterone......................................................... 45

Figure 1.5 Luteal Cell Progesterone Production............................................................ 46

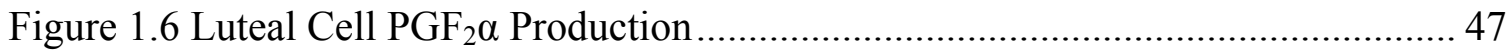

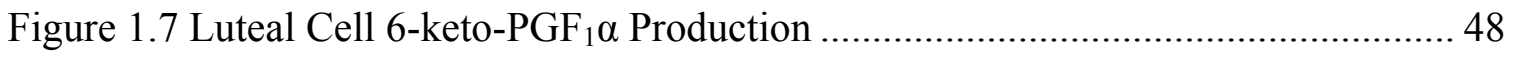

Figure 2.1 Representative Ultrasonographic Image ................................................. 59 


\section{ACKNOWLEDGEMENTS}

I would like to express my appreciation to the members of my committee, Drs.

Inskeep, Dailey, Hileman, Flores, Seidel, and Vernon for their guidance and contribution to my training. I would also like to thank the faculty of the Division of Animal and Nutritional Sciences and Health Sciences that were not members of my committee but that helped shape my experiences at WVU through teaching and mentoring. My sincere gratitude is also extended to the undergraduate work-studies and my fellow graduate students in Reproductive Physiology, Ruminant Nutrition, Biochemistry, and Biology. Their help made it possible to complete the research presented here and I have established valued friendships with many of them.

As for everything I have accomplished, family has been my primary support. I would like to thank my parents for their encouragement. Most of all, I have been blessed by the love and patience of my wife, Rachael and daughters, Sarah and Jenna. 


\section{REVIEW OF LITERATURE}

\section{Introduction}

Failure of lactating dairy cows to establish and maintain pregnancy is the most significant impediment to production efficiency in the United States dairy industry. Over the past four decades, conception rates for dairy cows that are artificially inseminated (AI) have declined from $65 \%$ to as little as 35\% (Santos et al., 2004). Several factors have been investigated as possible causes for the decline in reproductive efficiency of lactating dairy cows. These include the effects of semen quality (Dejarnette, 2005), selection pressure for increased production (Ferguson, 2005) and changes in nutritional management (Lucy, 2003). The magnitude of the impact of poor reproductive efficiency on the dairy industry can be illustrated by review of the economic consequences.

\section{Economic Impact of Pregnancy Loss}

Reproductive performance is one of the most important factors regulating profitability in U.S. dairy herds. The significance of poor reproductive efficiency is broad in scope; reproduction impacts many aspects of overall herd management. One of the most apparent influences of deficient fertility is increased calving intervals. Longer calving intervals are less profitable because of the associated decline in milk yield with duration of lactation. This becomes even more important when considering the timing of pregnancy loss. Early embryonic death extends the calving interval by one estrous cycle length if the return to estrus is detected. Late embryonic or early fetal loss increases the calving interval by the time required for resumption of cyclicity in addition to the number 
of days at which loss occurs (usually 28 to 60 days). Long calving intervals increase days in milk per lactation but reduce days in early lactation, the period of highest production per day, over a cow's productive life. Overall, extended calving intervals decrease the cow's lifetime milk production.

To estimate the economic benefits of improved reproductive performance through increasing pregnancy rates, De Vries and coworkers (2005) developed "The Florida Dairy Computer Program." This advanced economic modeling program was used to estimate the economic benefits of changed management practices. The model included variables such as lactation curves, body weights, efficiency of estrous detection, conception rates, risk of voluntary culling, labor, and feed intake. Costs considered included the prices of milk, feed, labor, veterinary services, semen, and estrous synchronization drugs. By using this comprehensive model, the authors estimated that the cost per cow per extra day open (beyond 80 days postpartum) varied from $\$ 0.81$ to $\$ 13.33$ and increased as days open increased (De Vries et al., 2005).

Other estimates support the concept that increased cost per day open is a compounding factor as calving intervals increase (Plaizier et al., 1997). These authors used a computer simulation program to estimate the impact of poor reproductive efficiency on profit for Canadian dairy herds. By their estimation, each day increase in adjusted calving interval reduced net revenue by a mean of $\$ 4.70$ (Canadian) per cow. Additionally, adjusted calving interval was more accurate in predicting economic impact because it included the cost due to reproductive culling rather than only the impact of calving interval on milk production. French and Nebel (2003), using a spreadsheet model to predict the economic impact of extended calving interval, estimated that each extra day 
open at 100 days in milk cost an additional $\$ 0.50$ and at 175 days cost an additional $\$ 4.52$ per day per cow.

The average value of a new pregnancy for an individual cow has been estimated by several authors. "The value of a pregnancy for an individual cow can be defined as the difference in discounted future cash flows when she is pregnant compared with when she is not pregnant" (De Vries, 2006). For timed insemination protocols, the estimated value of a new pregnancy was between $\$ 253$ and \$274 (Stevenson, 2001). Similarly, using a modified version of the previously described "Florida Dairy Computer Program," the average value of a new pregnancy for cows that differed in lactation number, stage of lactation and milk yield was \$278 (De Vries, 2006). The values reported by De Vries (2006) increased with days-in-milk early in lactation, but decreased with days-in-milk late in lactation.

Alternatively, the cost of "mid-term" abortion (days 42 to 260 days gestation) has been estimated to range from $\$ 600$ to $\$ 1,200$ (Piedrahita et al., 2002). The cost for midterm abortion in Canadian production systems, including reproductive loss and reduced milk yield, was estimated to be $\$ 1,286$ (US\$, Weersink et al., 2002). Although these reports were intended to illustrate the economic impact of pregnancy loss resulting from infectious diseases, the average cost of pregnancy loss at the transition to fetal development is similar for spontaneous pregnancy loss. These calculations illustrate the costs associated with reproductive failure after recognition of pregnancy.

Factors that interfere with the timely establishment of pregnancy and subsequent calving in lactating dairy cows reduce economic gain. Clearly, the amount of revenue potential lost by pregnancy wastage in dairy herds justifies research with the objective to 
identify its sources. The two points at which these factors might change the underlying biology of reproductive efficiency are: 1) fertilization and 2) pregnancy maintenance.

\section{Fertilization}

Reports of fertilization rates have varied but, on average, were similar for lactating and non-lactating dairy cows $(76.2 \%$ and $78.1 \%$ respectively; reviewed by Santos et al., 2004). However, the wide range of successful fertilization in that review (55.3 to $98.0 \%$ ) indicates that environmental impacts and management strategies likely affect the ability of the male and female gametes to establish a two-cell embryo. Fertilization rates tend to be less variable and more successful for nonlactating beef cows and heifers. Sreenan and Diskin (1983) reported a 90\% fertilization rate for beef heifers following a single AI, while Maurer and Chenault (1983) reported 100\% fertilization rate for parous beef cows pen-mated at the onset of estrus. However, fertilization rates for a series of studies of early postpartum lactating beef cows averaged $75 \%$, with a range from 61 to 100\% (Breuel et al., 1993). These findings are similar to those in lactating dairy cows and indicate an impact of lactation on fertilization success.

In each of the reports cited above, fertilization rate was considerably greater than calving rate. For the dairy herds reviewed by Santos et al. (2004), calving rates to first service were generalized to be $28 \%$. For beef heifers and cows, calving rates to single inseminations were reported to be only 53\% (Austin et al., 1999). Regardless of relative fertilization rate and breed type, the disparity between fertilization rate and number of calves born to a single insemination indicates an extremely high occurrence of pregnancy wastage from the time a zygote is created to parturition. 


\section{Pregnancy Loss}

Pregnancy loss can be defined broadly as death of the conceptus at any point from syngamy to parturition. However, as investigation of this phenomenon increased, terminology has been applied that delineates developmental periods during pregnancy. According to the Committee on Bovine Reproductive Nomenclature (1972), embryonic mortality is considered to be "the death or loss of conceptus during the embryonic period". This same committee recommended that the definition for the embryonic period set forth by Dennis (1969) be accepted: "the period from conception to the end of the stage of differentiation".

The embryonic period has been divided further into more concise periods of development. However, unlike much of the nomenclature used to describe periods of gestation, these terms have not yet been recognized formally but have advanced into common use in the literature. Early embryonic development refers to the period from fertilization to approximately day 20 of pregnancy. Late embryonic development indicates the period from days 20 to 45 post-fertilization. Fetal development is specified as the period of development from day 45 to term. More specifically, early fetal development refers to the period of gestation from completion of differentiation to day 60 post-fertilization (Committee on Bovine Reproductive Nomenclature, 1972).

\section{Early Embryonic Loss}

As reviewed by Aylon (1978), much of the early data collected for investigation of embryonic loss relied on determination of whether the post-insemination estrous cycle was longer than the previous or longer than would be considered average (17 - 25 days; 
Erb and Holtz, 1958). More precise determination of actual embryonic loss, independent of fertilization failure, came about with the implementation of timed slaughter of inseminated cows. Tanabe and Casida (1949) slaughtered repeat-breeding (anatomically normal with a minimum of four infertile services) cows at 3 and 34 days post-AI and found that $66.1 \%$ presented a fertilized ovum at day 3 while only $23.1 \%$ had a normal embryo at day 34. Normal cows exhibited less fertilization failure and less embryonic loss at day 35 (16 and 14.5\%, respectively; Ayalon, 1978).

Inskeep and Dailey (2005) reviewed the distribution of pregnancy failure from fertilization through transition to the fetal period. These authors concluded that the majority (57\%) of failed pregnancies occurred during early embryonic development, within one estrous cycle after insemination. In a review of the literature compiled upon request by the Commission of the European Communities, Sreenan and Diskin (1986) suggested that, for normal cows, "while embryo losses occur gradually from fertilization onwards, the greatest increment of losses would seem to occur between about days 15 and 18 ". They reached this conclusion by summarizing published fertilization rates for cows and heifers as "the number of normal cleaved ova or embryos as a proportion of all ova (fertilized or unfertilized) recovered" up to and including day 8 post-insemination. The fertilization rates for heifers and cows to natural mating or AI were $88 \%$ and $90 \%$, respectively (Sreenan and Diskin, 1986). They then compiled data from several other authors who employed oocyte and embryo recovery at various times after insemination. When considered together, these reports supported the authors' conclusion that most of the embryonic loss occurred between days 15 and 18 (Sreenan and Diskin, 1986). 


\section{Late Embryonic / Early Fetal Loss}

The period of development between approximately days 25 and 60 postinsemination is often referred to as late embryonic / early fetal development (Inskeep, 2004). Pregnancy loss during this developmental period constitutes a lower percentage of the total than earlier loss. However, the economic impact is significant because it results in an extended inter-estrous interval and more days in milk before a successful pregnancy is established (reviewed under heading "Economic Impact of Pregnancy Loss"). The frequency of late embryonic / early fetal pregnancy failure is easier to establish than early embryonic loss because the pregnancy can be observed by transrectal ultrasonography on gestation day 25 or detected by manual palpation on day 35 .

During the late embryonic / early fetal period of development, one of the most critical processes is placentation. Formation of an efficient system of nutrient and waste transfer between dam and fetus is required to take over support of fetal growth as the demand for nutrition becomes more than can be supplied by histotrophic maintenance from the uterus (Roberts and Bazer, 1988). Failure to form a proper and efficient placental transfer has been suggested as the factor leading to a majority of late embryonic loss that occurs between days 30 and 45 of gestation (Dailey et al., 2002). This concept was supported by Starbuck and coworkers (2004) who reported that most pregnancy loss after day 30 in dairy cows and heifers had occurred before day 42 post mating. To understand pregnancy wastage during placentation, placental development should be considered. 


\section{Placental Development}

The mammalian placenta is composed of three membranes: the chorion, allantois, and amnion. Each membrane has differing degrees of functional importance depending on species. For mammals, the chorion directly apposes the uterine endometrium and is responsible for generating the areas of nutrient and waste transfer between fetal and maternal circulation. The allantois produces the vasculature and hematopoetic potential that will create blood flow for placental function. The amnion develops primarily as a fluid-filled protective barrier against environmental insult to the fetus.

One of the first major steps in placental development is formation of the endoderm, mesoderm and ectoderm. This process, referred to as gastrulation, transforms the embryo into three primary germ layers that will give rise to all tissues and organs that comprise the mature mammal (Kaufman, 1995). Gastrulation begins with formation of the primitive streak, a group of cells that arise from the epiblast layer. The cells of the primitive streak then begin to migrate into the space between the epiblast and hypoblast. Cells that will become endoderm move into the hypoblast and displace it into the extraembryonic space. Cells that will become mesoderm populate the area between the epiblast and hypoblast. The ectoderm is composed of the remaining cells of the epiblast. The embryo becomes elongated as these cell layers begin to migrate and differentiate. Contact between the germ layers is responsible for stimulating organogenesis, the next major progression in embryogenesis (Kaufman, 1995). Relatively small changes in the local environment or disregulation of genetic control for this process can impact development of the embryo and its extraembryonic membranes. 
Chorion: Two layers of differing cellular origin comprise the chorion: the trophoblast and mesoderm. The trophoblast is the outer layer of the chorion that contacts uterine endometrium, and the inner mesodermal layer contacts the amnion. The trophoblast includes two distinct cellular types; an internal layer of cuboidal cells called cytotrophoblast and an external layer of cells called syncytiotrophoblast. By definition (syncytium), these cells become multinucleated by either karyokinesis without cell division or by the fusion of several mononucleated cells. For mammalian embryos that implant into the endometrium, this layer is highly invasive near the inner cell mass. For the horse and human being, the syncytiotrophoblast produces placental gonadotropins (equine chorionic gonadotropin, eCG and human chorionic gonadotropin, hCG; respectively) as luteotropins. Binucleate giant cells, also of chorionic origin, are unique to the ruminant and produce pregnancy specific protein B. Cells originating from the cytotrophoblast are responsible for placental steroid production.

Classification of placental relationship with the uterus is based on the number of tissue layers that separate the fetal and maternal blood. The epitheliochorial placenta presents the highest degree of maternal and fetal separation. In this situation, both the endometrial epithelium and the epithelium of the chorionic villi remain intact. This type of placentation is found in ruminants as well as in the mare and sow. Lack of intimate apposition of blood flow is offset by a large placental surface area in the sow and mare and by increased efficiency of transfer in ruminants. The endotheliochorial placenta, as for dogs and cats, lacks endometrial epithelium such that maternal capillaries are directly exposed to chorionic epithelium. Direct exposure of chorionic epithelium to pools of maternal blood is referred to as a hemochorial placenta (primates). Finally, 
hemoendothelial placenta (rat, rabbit and guinea pig) is the most intimate type as the placental vasculature is immersed in pools of the maternal blood.

Allantois: In Knobil and Neill's Encyclopedia of Reproduction, the allantois is defined as "a membrane that develops as an evagination of the hindgut to form a sac filled with water, urine, and nutrients" (Bazer, 1998). It begins as a diverticulum of endoderm covered by mesoderm. For cattle, the allantois begins to develop on approximately day 20 post-fertilization (Flechon and Renard, 1978; Greenstein et al., 1958). It continues to grow and fill with allantoic fluid until it occupies the extraembryonic space and contacts the chorion.

Greenstein and coworkers (1958) used serial slaughter of heifers and cows to characterize gross anatomical and histological features of the bovine preattachment placenta from days 16 to 33 of gestation. They stated that, on days 21 and 22, "the allantoic diverticuli have become a constant feature of embryos at this age and the enlarging distal portions approach a centimeter in length.” During days 23 to 25 , the allantois continues to expand rapidly, is becoming highly vascularized and ranges from 0.8 to $5.5 \mathrm{~cm}$ in length. On days 26 and 27, the allantoic vesicle ranges in length from 5.5 $\mathrm{cm}$ to $11.0 \mathrm{~cm}$. During days 28 to 30 of gestation, the allantois has begun to fuse with the "overlying trophoderm" and contains an extensive network of vessels filled with nucleated fetal red blood cells (Greenstein et al., 1958).

The ultrastructural characterization of post-hatching development for the bovine embryo was reported recently (Maddox-Hyttel et al., 2003). For seven, day-21 embryos, gestated together as a result of superovulation and breeding on day 0 , the length of the embryo ranged from 3.14 to $5.79 \mathrm{~mm}$ while the allantois ranged in width from 1.15 to 
$4.41 \mathrm{~mm}$. The authors noted "a clear relationship between the embryo length and width of the allantois", but provided no statistical analysis to support the comment. The allantois had not yet developed for two embryos that were 3.14 and $3.77 \mathrm{~mm}$ long (Maddox-Hyttel et al., 2003).

Recently several genes have been identified as being expressed differentially during allantoic emergence in bovine and ovine conceptuses (Ledgard et al., 2006). These authors used suppressive subtractive hybridization to compare mRNA expression in preimplantation conceptuses prior to emergence of the allantois and in allantoic samples after emergence. Nine genes were identified as differentially expressed. All were associated with extracellular matrix and vasculogenesis. Similarly, Ushizawa et al. (2004) used cDNA microarray analysis to determine gene expression profiles in the bovine embryo during the preattachment period. They found differential expression of more than 1,000 genes on days 7, 14, 21 and 28. Comparison of extra-embryonic membranes and the embryo proper on day 28 revealed 119 down-regulated genes and 74 up-regulated genes in the membranes. The up-regulated genes included placental lactogen, prolactinrelated proteins, pregnancy associated glycoproteins, and major histocompatibility complex molecules.

A great deal of focus has been placed on development of the murine allantois (Downs et al., 2004). Results from several of these experiments indicated that development of the allantois requires both intrinsic mechanisms and communication with the primitive streak. Recall that the primitive streak is a thickening at the midline of the epiblast from which the endoderm and mesoderm differentiate and move to appropriate sites in the conceptus (Poelmann, 1981). The posterior primitive streak is the site of 
origin of the allantoic bud. Extraembryonic mesoderm accumulates between the amnion and yolk sac and enlarges into the exocoleomic cavity by proliferation, continuous deposition of mesoderm from the streak, and distal cavitation (Ellington, 1987).

Vascularization of the murine allantois arises from an outer layer of mesothelium and an inner layer of mesoderm (Downs, 1998). Formation of endothelium occurs de novo in the allantois. Endothelial tubules begin to form at the distal region, proceed proximally to the base of the allantois, and join with the yolk sac to create a continuous vasculature throughout the conceptus (Downs, 1998). Eventually, the plexus of vasculature in the allantois is transformed into the umbilical vein and artery (Kaufman, 1995).

Unlike the yolk sac, in which development of blood islands depends on contact with endoderm (Belaoussoff et al., 1998), the allantoic mesoderm grows into the exocoelomic cavity as an independent structure that does not contact other tissue until after the allantoic endothelium and mesothelium have developed (Downs, 1998). Therefore, it would appear that development of the allantois is guided either by intrinsic factors or by the primitive streak. When detached portions of allantoic membrane were inserted into the exocoelomic cavity of synchronous hosts, they attached to the host chorion at the appropriate time (Downs and Gardner, 1995). Furthermore, when murine allantoises were cultured apart from the conceptus, they developed normal vascularization (Downs and Harmann, 1997). Both of these observations support the concept that allantoic development is directed by intrinsic factors.

Differentiation of the allantois into endothelial and chorio-adhesive cells begins in the region furthest from the primitive streak (Downs and Harmann, 1997). Downs and 
coworkers (2004) hypothesized that the primitive streak controls cellular differentiation because the expression of vascular cell adhesion molecule (VCAM1; an adhesion molecule specific to chorio-adhesive cells) was limited to the distal regions of the allantois (Gurtner et al., 1995). When mesoderm from the primitive streak (precursor of allantoic tissue) was transplanted into the distal region of recipients, it exhibited limited development (Dunwoodie and Beddington, 2002). Similarly, when newly budded mesoderm of the primitive streak was transplanted to distal regions of hosts, it contributed only to blood vessels and not to somatic mesoderm (Downs and Harmann, 1997). Taken together, the results of these studies indicated that allantoic endothelial cells are specified within the primitive streak.

From the results discussed in the two previous paragraphs, it appears that differentiation of cell types found in the murine allantois is determined in the primitive streak before it begins to bud from the embryo proper. After differentiation, development is guided by intrinsic factors until the allantois contacts the chorion. However, it is not completely independent of the embryo because, as it continues to develop and grow into the exocoelomic cavity, the primitive streak maintains contribution of mesoderm to the membrane. The hypothesized intrinsic factors seem to be regulated by age of the cells, due to the pattern of development beginning at the portion of the allantois distal to the primitive streak.

\section{Frequency of Late Embryonic / Early Fetal Loss}

Several reviewers have compiled data from field trials that describe the rate of pregnancy failure from pregnancy diagnosis (gestation days 25 or 30) until the early fetal period (gestation days 45, 60, 80 and/or 100). Smith and Stevenson (1995) reported an 
average "late embryonal loss" of $12.4 \%$ for cows and heifers bred after several different estrous synchronization protocols. Pregnancy survival was not altered by method of synchronization but tended to be higher in heifers than in multiparous cows (Smith and Stevenson, 1995). Vasconcelos et al. (2003) reported 10.5\% pregnancy loss between days 28 and 42 of gestation for lactating dairy cows.

Milk progesterone has been used to identify luteal phases presumed to have been extended ( $>24$ days) by early pregnancy. Using this method, several authors have reported the frequency of pregnancy loss up to day 100 post-insemination (Kummerfeld et al., 1978; Bulman and Lamming, 1979; Grimard et al., 2006). These estimates ranged from $7 \%$ to $25.2 \%$ and agreed with the ranges reported in the reviews by Dailey et al. (2002) and Inskeep (2004). Humbolt (2001) reported that late embryonic mortality ranged between 8 and 17\% with a mean of 14\%. More recently, Grimard et al. (2006) reported that season and body condition score (BCS) affected pregnancy loss between pregnancy days 21 and 100 despite not affecting conception rates.

\section{Effects of Low Progesterone on Pregnancy Loss}

The effect of progesterone on embryonic survival in the cow has been reviewed (Inskeep, 2004). In part, that review focused on the effect of progesterone on growth dynamics of the preovulatory follicle and how those changes affect early embryonic development. When circulating concentrations of progesterone or progestagen were low, follicles were maintained in a static growth phase while ovulation is inhibited (Imwalle et al., 2002). When follicles were forced to persist, fertility at the resulting ovulation was compromised (Stock and Fortune, 1993; Smith and Stevenson, 1995). This decrease in fertility can be traced to poor oocyte quality resulting from follicular persistence (Austin 
et al., 1999; Revah and Butler, 1996). The oocyte can be fertilized, but development of the resulting embryo is interrupted (Ahmad et al., 1995).

Late embryonic / early fetal losses in dairy cows have been associated with low circulating concentrations of progesterone (Starbuck et al., 2004). In this study, the authors evaluated cows bred to either spontaneous or synchronized estrus and by AI or natural service. Pregnancy was diagnosed on days 28 to 37, and blood samples were collected for quantification of progesterone and estradiol. Pregnant cows were examined again between days 45 to 51 and between days 59 and 66. Overall pregnancy loss between days 28 to 37 and 59 to 66 was 11.4\% (Starbuck et al., 2004). This result agreed with the averages reported by reviewers of late embryonic / early fetal mortality (Kummerfeld et al., 1978; Dailey et al., 2002; Inskeep and Dailey, 2005). Pregnancy loss before day 45 was greater for cows in the lowest 25 th percentile of circulating progesterone concentrations ( 0.4 to $3.7 \mathrm{ng} / \mathrm{mL} ; 20 \%)$ on days 28 to 37 than for cows in the middle $50 \%$ (3.9 to $5.9 \mathrm{ng} / \mathrm{mL} ; 4 \%$ ) or upper $25 \%$ (6.0 to $17.0 \mathrm{ng} / \mathrm{mL} ; 4 \%$; Starbuck et al., 2004).

The cause of low concentrations of progesterone in peripheral circulation is not yet certain. It could be due to low luteal progesterone production, increased progesterone metabolism or both. Sangsritavong et al. (2002) reported an acute increase in liver blood flow and metabolic clearance rate for progesterone and estradiol $17 \beta$ in lactating and nonlactating dairy cows fed above maintenance. They indicated that this difference in metabolic clearance of infused steroids could be responsible for reduced fertility in highproducing dairy cows that had increased feed intake (Sangsritavong et al., 2002). 
Lower circulating concentrations of progesterone and estradiol for lactating cows compared to heifers, in spite of the fact that follicular and luteal volumes were greater in cows, might indicate a difference in metabolic clearance (Sartori et al., 2004). This same group of authors compared dry and lactating dairy cows. They found that follicles and luteal structures were larger for lactating cows, but peripheral concentrations of estradiol and progesterone did not differ (Sangsritavong et al., 2002). This might indicate that the added metabolic demand of lactation leads to compensatory growth and function of steroidogenic ovarian structures.

\section{Pregnancy Loss Associated with Assisted Reproductive Technology}

While the timing of embryonic and fetal death has been well characterized and the frequency of pregnancy failure in cattle has been associated with several hormones, changes in the molecular biology of conceptuses that lead to late embryonic or early fetal death have not been determined. Other situations that lead to poor reproductive efficiency might prove to be useful tools for developing hypotheses to be tested in lactating dairy cows. One such situation is in vitro production of bovine embryos.

Calving rates from transfer of in vitro-produced bovine embryos to apparently normal recipient cows or heifers are poor. The degree to which reproductive success is altered depends on the method of fertilization and type of culture system used. Even though the amount of loss is substantially more, the timing of pregnancy failure for these situations often resembles the timing of both early embryonic and late embryonic / early fetal losses for AI-derived pregnancies in dairy cattle. Therefore, studying pregnancy failure from embryos produced by in vitro fertilization (IVF) and somatic cell nuclear 
transfer (SCNT) cloning might provide new insight into pregnancy loss for AI pregnancies in dairy cows and heifers.

Embryos produced by IVF and SCNT cloning exhibit differences in morphology, gene expression and developmental ability (Crosier et al., 2001; Farin et al., 2001; Hansen and Block, 2004; Hasler, 2000) when compared to in vivo-produced embryos. Embryos produced by IVF have higher rates of embryonic mortality than those produced by AI (Hansen and Block, 2004; Hasler, 2000). Farin (2001) reported that the majority of pregnancy loss after transfer of IFV-produced embryos occurred before day 21 of gestation. In this study, $19 \%$ of the IVF embryos recovered on day 17 were degenerating compared to none of the in vivo produced and transferred embryos (Farin et al., 2001).

Survival rates to term for SCNT-cloned bovine embryos ranged from $0 \%$ to $80 \%$ (Kato et al., 1998; Piedrahita et al., 2002). Hill and coworkers (2000) reported survival rates for embryos derived in vivo or by SCNT. At day 30 of gestation, there was no difference in pregnancy rates of recipients receiving in vivo- or SCNT-produced embryos. However, the in vivo group received one embryo per recipient while the other group received two cloned embryos. By day 90 of gestation, $82 \%$ of the SCNT pregnancies were terminated while all the in vivo-derived pregnancies survived. Pregnancy loss for the SCNT group was distributed evenly over the 60 -day period with $35 \%$ dead on day 40 , an additional $32 \%$ dead on day 60 and $15 \%$ more dead on day 90 (Hill et al., 2000). In a similar study, pregnancy rates for recipients that received only one embryo produced by IVF or SCNT cloning were similar to each other and not different from AI pregnancies, on day 50 of gestation (De Vries et al., 2005). No pregnancy loss occurred for AI and 
IVF embryos, but the SCNT embryos continued to die until only $40 \%$ of those fetuses remained on gestation day 150 (De Vries et al., 2005).

\section{Allantoic Development for IVF and SCNT embryos}

A majority of the embryonic mortality between days 30 and 60 of gestation for IVF- and SCNT-derived pregnancies can be attributed to improper development of the allantois (Hill et al., 2000). The allantois is the critical link for developing an efficient placenta that will be able to support fetal development beyond the transition away from histotrophic support. Using serial slaughter of recipient cows that received an IVF embryo or were artificially inseminated, it was determined that the degree of malformation of the allantois ranged from aplasia to normal growth and vascularization without haematopoesis (Piedrahita et al., 2002).

Size of the follicle donating an oocyte for IFV affected placental development of the resulting embryo (Piedrahita et al., 2002). The length and width of the allantois on day 27 of gestation were smaller for embryos derived from small than from large follicles. However, there was no difference in length and width of the embryo proper or the degree of vascularization of the allantois in relation to follicular size. In addition to differences in growth rate of the allantois, these authors reported a difference in the ability of the allantois to fuse with the chorion. For all 17 conceptuses derived from small follicles, the allantois and chorion detached during collection. In contrast, 14 of 18 conceptuses derived from large follicles presented fully fused chorioallantoic membranes that could not be detached manually after collection (Piedrahita et al., 2002). These findings hold particular interest in relation to the reports of increased embryonic loss for 
cows bred to ovulation of either immature (Perry et al., 2005) or persistent (Ahmad et al., 1995) follicles.

As reviewed here, and considered in light of the information gained from recent studies that characterize the genes controlling allantois development, new hypotheses can be tested to determine particular alterations caused by IVF and SCNT cloning. Moreover, when the genetic aberrations that lead to poor allantoic development are elucidated, their patterns of expression can be compared in AI pregnancies that are destined to succeed or fail during placentation. However, at this time, methods to determine the pattern of allantoic development without termination of the pregnancy have not been reported.

\section{Ultrasonographic Evaluation of Embryonic Development}

Transrectal ultrasonography holds promise as a non-invasive tool to observe extraembryonic membrane development. Use of ultrasonography to observe reproductive anatomy in cattle has allowed investigators to characterize changes in the gross anatomical features of the ovary, uterus and conceptus. More recently, Doppler ultrasonography has been used to measure changes in blood flow to and from tissues. Texture analysis or quantification of pixel intensity can now be used to make inferences about tissue ultrastructure.

Researchers at the University of Wisconsin were among the first to monitor embryonic and fetal development in the cow (Pierson and Ginther, 1984; Curran et al., 1986a, 1986b; Kastelic et al., 1989, 1991). Average first detection of the embryonic vesicle in heifers occurred on day 19 post-insemination when a $5 \mathrm{MHz}$ transducer was used (Curran et al., 1986a). Using a transducer with greater resolution $(7.5 \mathrm{MHz})$ to image the reproductive tract of cows, the embryonic vesicle was reported to have been 
observed as early as day 9 post-insemination (Boyd et al., 1988) but those results have not been repeated.

Average first day of detection of the embryo proper, as a small echoic spot in a bulged area of the vesicle, was day 20 for Curran and colleagues (1986a). Boyd et al. (1988) reported to have found the embryo proper on day 13. On average, the heartbeat was detected on days 21 (Boyd et al., 1988) or 22 (Curran et al., 1986b). Curran and others (1986a) reported average heart rate of 188 beats-per-minute on the first day of detection. In a more recent study, the average first days of detection of the embryo and embryonic heartbeat were 24 and 28, respectively (Kolour et al., 2005). These authors used an $8 \mathrm{MHz}$ probe. It is interesting to note the variability for day of first detection of the vesicle and embryo proper. However, the first day of detection for structures developing later in gestation becomes more consistent.

Each of the authors cited above reported the first day of detection of the allantois. On average, the allantois was detected first by Curran and colleagues (1986b) on day 23 post-insemination. Similarly, Boyd and others (1988) reported first observing the allantois on day 23 . Though reporting a similar range, parity of the dam affected the timing of detection of the allantois by the Iranian group (Kolour et al., 2005). They first observed the allantois on days 22, 23 and 26 in heifers, primiparous and multiparous cows, respectively. The day of detection of the allantois was similar for heifers and primiparous cows and each was statistically different than multiparous cows. In their discussion, Kolour et al. (2005) suggested that the relatively large size of the uterine horns affected their ability to detect structures earlier in multiparous cows. However, the possibility that embryonic development occurs at a faster rate in heifers and younger 
cows cannot be excluded. This concept would be supported by the proposal that increased circulating progesterone, as a result of lower average milk production, maintains more histotrophic support, similar to that demonstrated in the ewe (Satterfield et al., 2006). 


\section{STATEMENT OF THE PROBLEM}

Currently, reproductive efficiency is poor for lactating dairy cows. Embryonic mortality occurs more frequently during early embryonic development (days 1 to 20 postinsemination) than late embryonic / early fetal development (days 20 to 45 post insemination Sreenan and Diskin, 1986). However, when pregnancy failure occurs during late embryonic / early fetal development, the inter-estrous interval, calving interval and days in milk are all increased beyond the length of one estrous cycle. Increased calving interval decreases the time a cow is in peak production over her lifetime and decreases profit.

Pregnancy wastage during late embryonic / early fetal development averages 10 to $15 \%$ for dairy cattle. For contemporary production scenarios, loss of a pregnancy at this time constitutes a revenue loss of $\$ 600$ (De Vries, 2006). For the US dairy herd (approximately 9 million cows; US Agriculture Census, 2002) an average of $12 \%$ pregnancy wastage at placentation would mean a revenue loss of $\$ 6.5$ million. Clearly, finding management techniques or treatments that reduce the amount of late embryonic / early fetal loss would have a significant impact on the profitability of dairy production.

The main objective of these experiments was to determine causes of pregnancy loss during placentation in dairy cattle. One specific objective was to determine if decreased circulating concentration of progesterone at this time, with which pregnancy loss is known to be associated, is due to decreased luteal secretion of progesterone or to increased metabolism of progesterone. To address this objective, corpora lutea were removed from cows determined to fall in the low and high classifications of circulating progesterone as determined by the work of Starbuck et al. (2004). Luteal function was 
evaluated while the fate of supplemental progesterone was monitored for cows after CL removal.

A second objective was to determine if growth characteristics of the allantois could be observed by transrectal ultrasonography and if pregnancy loss up to day 60 postinsemination was associated with these characteristics. To evaluate these questions, late embryonic development in dairy cows and heifers was monitored daily by transrectal ultrasonography. Allantoic growth traits were compared between cows and heifers and with regard to development of the embryo proper. 


\section{LUTEAL FUNCTION AT DAY 30 OF PREGNANCY IN RELATION TO SERUM PROGESTERONE IN DAIRY COWS AT RISK FOR LATE EMBRYONIC OR EARLY FETAL MORTALITY}

\section{Abstract}

Pregnancy failures during placentation in lactating dairy cows have been associated with low concentrations of peripheral serum progesterone $\left(\mathrm{P}_{4}\right)$. Experiments were done to determine if pregnant cows with high or low concentrations of serum $\mathrm{P}_{4}$ differed in luteal production of $\mathrm{P}_{4}$ and/or clearance of injected $\mathrm{P}_{4}$. Luteal tissue was removed from pregnant cows with $\geq 4.0 \mathrm{ng} / \mathrm{mL}$ (High) or $\leq 2.5 \mathrm{ng} / \mathrm{mL}$ (Low) serum $\mathrm{P}_{4}$ during d 28 to 34 post-insemination. Luteal tissue was assayed for $\mathrm{P}_{4}$ by radioimmunoassay and for expression of mRNA for preproendothelins 1 and 3, endothelin converting enzyme, endothelin receptors A and B, cyclooxygenase-2, aldoketoreductase 1B5, 15hydroxyprostaglandin dehydrogenase, and prostaglandin E synthase by real-time RTPCR. Dispersed luteal cells were incubated for $2 \mathrm{~h}$ with bovine luteinizing hormone (bLH) or arachidonic acid (AA), increasing $\left(10^{-10}\right.$ to $\left.10^{-7} \mathrm{M}\right)$ concentrations of endothelin-1 (ET-1), and combinations of ET-1 and bLH or AA. Neither luteal content of $\mathrm{P}_{4}$ (mean $106 \pm 12 \mu \mathrm{g}$ ) nor mRNAs for the endothelin or prostaglandin systems differed with serum $\mathrm{P}_{4}$ at lutectomy. Both basal and LH-stimulated secretion of $\mathrm{P}_{4}$ from dispersed luteal cells were inhibited $(\mathrm{P}<0.05)$ by ET-1 in a dose dependent manner. Inhibition by ET-1 was greater $(\mathrm{P}<0.05)$ for luteal cells from Low vs. High cows when incubated with AA. Both basal and AA-stimulated secretion of $\mathrm{PGF}_{2} \alpha$ by luteal cell culture were increased by ET-1 in a dose-dependent manner. Basal and AA-stimulated 6-keto-PGF $1 \alpha$ were decreased by ET-1 in a dose-dependent manner. To evaluate clearance of $\mathrm{P}_{4}$, cows were injected s.c. with $150 \mathrm{mg} \mathrm{P}_{4}$ every $12 \mathrm{~h}$ beginning at lutectomy. In jugular blood 
collected every 4 h until h 48 , serum $\mathrm{P}_{4}$ was maintained at lower $(\mathrm{P}<0.05)$

concentrations for Low vs. High cows. Area under the curve was less $(\mathrm{P}<0.05)$ for Low $(49.6 \pm 6.2)$ than for High $(83.6 \pm 3.3)$ cows. On the basis of these data, differences in clearance were more important than differences in luteal production to determine peripheral concentrations of $\mathrm{P}_{4}$. However, culture with ET-1 and AA caused a greater reduction of $\mathrm{P}_{4}$ production for luteal cells from cows with Low than High serum $\mathrm{P}_{4}$. Thus, CL of Low cows might be more sensitive to luteolytic influences than CL of High cows. Reduced clearance of $\mathrm{P}_{4}$ might decrease late embryonic or early fetal mortality as efficiently as supplementation with exogenous progestogens.

\section{Introduction}

Failure of lactating cows to establish and maintain pregnancy is a significant impediment to production efficiency. Over the past four decades, conception rates to a single service for artificially inseminated (AI) dairy cows have declined from around $65 \%$ to as little as $35 \%$ (Santos et al., 2004). Several factors have been investigated as possible causes for the decline, including semen quality (Dejarnette, 2005), selection pressure for increased production (Ferguson, 2005), and changes in nutritional management (Lucy, 2003).

During the late embryonic / early fetal period of development (d 30 to 60 postinsemination) formation of an efficient system for transfer of nutrients and wastes between dam and fetus is required to support fetal growth as the demand for nutrition becomes more than can be supplied by histotroph (Roberts and Bazer, 1988). Failure to form an appropriate placental transfer system has been suggested as the factor leading to a majority of the embryonic losses that occur between d 30 and 45 of gestation (Dailey et 
al., 2002). Starbuck and coworkers (2004) reported that most pregnancy loss after d 30 in dairy cows and heifers had occurred before $\mathrm{d} 42$ post mating, the time at which embryonic development can no longer be supported by uterine histotroph alone. In addition, losses were greater in association with low circulating concentrations of progesterone around d 30 of pregnancy. Low concentrations of progesterone in peripheral circulation of pregnant cows could be due to low luteal production of progesterone, increased metabolism of progesterone or both. Much of the current research supports the hypothesis that lower progesterone during the estrous cycle is due to increased metabolism (Wiltbank et al., 2006). Sangsritavong et al. (2002) reported acute increases in liver blood flow and metabolic clearance rates for progesterone and estradiol-17 $\beta$ in lactating and non-lactating dairy cows fed above maintenance. A series of studies using Holstein-Friesian dairy cows established that greater feed intake reduced serum concentrations of progesterone during the luteal phase or during treatment with exogenous progesterone via subcutaneous injection or a controlled internal drug releasing device (Rabiee et al., 2001ab, 2002ac).

Other studies have been focused on luteal secretion of progesterone. One area of investigation has been interactions of the prostaglandin (PG) and endothelin systems. The inhibitory effect of $\mathrm{PGF}_{2} \alpha$ on luteal progesterone production in vitro was observed in luteal slices and large steroidogenic luteal cells only when co-cultured with endothelial cells (Girsh et al., 1995) indicating that $\mathrm{PGF}_{2} \alpha$ might influence steroidogenic cells indirectly through endothelial cells. The endothelin system includes a group of at least 6 genes that encode a family of signaling peptides, receptors, and converting enzymes (Meidan and Levy, 2002). In bovine CL, synthesis of ET-1 has been demonstrated by the 
presence of ET-1 protein and mRNA (Girsh et al., 1996a). Addition of ET-1 reduced in vitro production of progesterone by dispersed luteal cells from midcycle CL (Girsh et al., 1995; Hinckley and Milvae, 2001). Furthermore, in the midluteal phase of the bovine estrous cycle, $\mathrm{PGF}_{2} \alpha$ stimulated expression of preproendothelin-1 (Girsh et al., 1996b). Therefore, ET-1 might mediate the luteolytic effects of $\mathrm{PGF}_{2} \alpha$. Both $\mathrm{PGF}_{2} \alpha$ and ET-1 appear to be required for functional luteolysis (Hayashi et al., 2003).

Choudhary et al. (2004) suggested that expression of the the endothelin system is regulated by both $\mathrm{PGF}_{2} \alpha$-independent and dependent pathways. They measured luteal expression of mRNA for prepro-ET-1 on d 1, 4, 10 and 17 of the bovine estrous cycle. It increased from $\mathrm{d} 1$ to $\mathrm{d} 4$ and 10 and was not changed by administration of $\mathrm{PGF}_{2} \alpha$ ( $\mathrm{PGF}_{2} \alpha$-independent phase). On d 17, ET-1 mRNA expression was increased by exogenous $\mathrm{PGF}_{2} \alpha$ compared to saline injection ( $\mathrm{PGF}_{2} \alpha$-dependent phase). In a subsequent experiment, ET-1, but not $\mathrm{PGF}_{2} \alpha$, inhibited tonic secretion of progesterone from d 4 luteal cells (Choudhary et al., 2005). These findings led to the hypothesis that the ability of $\mathrm{PGF}_{2} \alpha$ to decrease production of progesterone develops as its signal transduction cascade matures, at which point $\mathrm{PGF}_{2} \alpha$ and ET-1 can act together to facilitate luteolysis. By testing this hypothesis, Sen and coworkers (2006) found that conventional protein kinase $\mathrm{C}$ (PKC) isozymes mediate inhibitory effects of ET-1 on progesterone secretion in the $\mathrm{d} 4 \mathrm{CL}$. A specific isozyme, $\mathrm{PKC} \varepsilon$, was detected only in steroidogenic cells, increased from $\mathrm{d} 4$ to 10 , and likely modulates the ability of $\mathrm{PGF}_{2} \alpha$ to reduce progesterone secretion (Sen et al., 2005, 2006).

The uterus traditionally has been considered the primary source of luteolytic $\mathrm{PGF}_{2} \alpha$ in the cow. However, early reports demonstrated that corpora lutea of domestic 
animals produced significant amounts of $\mathrm{PGF}_{2} \alpha$ (Shemesh and Hansel, 1975; Patek and Watson, 1976). Watson and Patek (1979) reported reduced secretion of $\mathrm{PGF}_{2} \alpha$ by luteal tissue of pregnant pigs compared to pigs that were late in the estrous cycle. Subsequently, Rexroad and Guthrie (1979) and Guthrie et al. (1979) showed that corpora lutea of ewes and pigs, respectively, secreted more $\mathrm{PGF}_{2} \alpha$ after treatment with exogenous $\mathrm{PGF}_{2} \alpha$ to induce luteolysis. Wade and Lewis (1996) confirmed that exogenous $\mathrm{PGF}_{2} \alpha$ stimulated utero-ovarian secretion of $\mathrm{PGF}_{2} \alpha$, as shown by an increase in $\mathrm{PGF}_{2} \alpha$ in vena caval plasma in intact, but not in hysterectomized / ovariectomized ewes.

Similar studies in the cow revealed that synthesis of $\mathrm{PGI}_{2}$ (measured as its metabolite 6-keto-PGF $1 \alpha$ ) and $\mathrm{PGF}_{2} \alpha$ by luteal cells in vitro varied with stage of the estrous cycle (Milvae and Hansel, 1983). Tsai and Wiltbank $(1997,1998)$ proposed that secretion of $\mathrm{PGF}_{2} \alpha$ from the corpus luteum, in an autocrine or paracrine manner, amplifies the endocrine luteolytic signal from the uterus. A single injection of $\mathrm{PGF}_{2} \alpha$ upregulated mRNA encoding prostaglandin G/H synthase 2 (PGHS-2, COX-2) in midand late cycle ovine and bovine corpora lutea, but was not effective in animals on $\mathrm{d} 4$ of the estrous cycle. Arosh et al. (2004) proposed that increased luteal prostaglandins mediate luteolysis because the enzymatic activity has shifted to favor synthesis of $\mathrm{PGF}_{2} \alpha$ rather than $\mathrm{PGE}_{2}$.

Whether low circulating concentrations of progesterone in pregnant cows are the result of decreased luteal production, increased clearance, or both, has yet to be directly and simultaneously investigated during pregnancy in the lactating dairy cow. Therefore, the first objective of this study was to compare: 1) steroidogenic function, 2) expression 
of enzymes involved in synthesis and degradation of prostaglandins, and 3) expression of components of the luteal endothelin system of CL collected from cows with low or high peripheral progesterone on d 30 of pregnancy. The second objective was to compare concentrations of progesterone in peripheral blood of these cows when a standard dosage of progesterone was injected after lutectomy.

\section{Materials and Methods}

Lactating cows in the West Virginia University herd were examined by transrectal ultrasonography for the presence of a viable embryo with a heartbeat on d 28 to 34 of gestation. Days postpartum at initial blood sample averaged $102 \pm 8.2$. A blood sample was collected from the jugular vein, allowed to clot for $6 \mathrm{~h}$, and serum was assayed immediately for progesterone so that the results were available the next morning. Only cows with concentrations of progesterone $\leq 2.5 \mathrm{ng} / \mathrm{mL}$ (Low) or $\geq 4.0 \mathrm{ng} / \mathrm{mL}$ (High) were selected for the study ( $\mathrm{n}=7$ Holstein and 5 Ayrshire). These criteria were chosen based on the report by Starbuck et al. (2004) and intended to provide a comparison of cows that have an increased risk of pregnancy loss (Low) with cows that would be expected to have a greater pregnancy retention rate (High). All procedures were approved by the Animal Care and Use Committee of West Virginia University (ACUC \# 03-0402).

Immediately prior to lutectomy, size of the corpus luteum (vertical by horizontal diameter) and embryonic viability were determined via transrectal ultrasonography. Corpora lutea were removed via supravaginal incision as described by Casida (1959), under epidural anesthesia with $2 \%$ lidocaine hydrochloride, the day after initial sampling for circulating progesterone concentration. Luteal tissue was placed in cold physiological saline and immediately transported to the laboratory for further processing. A portion of 
the tissue was minced with a sterile scalpel in cold Medium 199 (M 199; GIBCO, Carlsbad, CA) and shipped, on ice, overnight to the University of Connecticut for luteal cell incubation. The remaining luteal tissue was cubed, snap-frozen in liquid nitrogen, and stored at $-80^{\circ} \mathrm{C}$.

Jugular blood samples were taken every $4 \mathrm{~h}$ beginning at lutectomy (h 0 ) and continuing through $\mathrm{h} 48$. Samples were allowed to clot for $12 \mathrm{~h}$, centrifuged at $1,500 \times \mathrm{g}$ for $30 \mathrm{~min}$, and two aliquots of serum were stored at $-20^{\circ} \mathrm{C}$. Beginning immediately after blood sampling at $\mathrm{h} 0$, progesterone $(150 \mathrm{mg})$ was injected subcutaneously every $12 \mathrm{~h}$ until the last blood sample was taken. This dosage was used in earlier studies (Bridges et al., 2000; Starbuck et al., 2004) to successfully maintain pregnancy in cows lutectomized at various times from day 5 to 35 . Milk was discarded during and after treatment with exogenous progesterone as directed by the United States Food and Drug Administration. Real-Time RT-PCR. Expression of messenger ribonucleic acid (mRNA) for preproendothelin-1, preproendothelin-3, endothelin receptor-A, endothelin receptor-B, endothelin converting enzyme-1, cyclooxygenase-2, aldoketoreductase 1B5, prostaglandin 15-dehydrogenase, and prostaglandin E synthase in luteal tissue was measured by quantitative real-time PCR. Total RNA was isolated from frozen luteal tissue using Trizol reagent according to the manufacturer's instructions (GIBCO BRL, Gaithersburg, MD). RNA quality was determined by separation and visualization on a $1.5 \%$ agarose gel stained with ethidium bromide and quantified spectrophotometrically at $260 \mathrm{~nm}$. For each sample, $2 \mu \mathrm{g}$ of DNAse-treated total RNA was reverse transcribed to first-strand cDNA using oligo (dT)18 primer and Superscript II reverse transcriptase (Invitrogen, Carlsbad, CA). Negative control reverse transcription reactions without the 
enzyme were carried out to confirm that there was no contamination with genomic DNA. Real-time PCR primers for the genes listed above and the control gene glyceraldehyde-3phosphate dehydrogenase (GAPDH) were designed based on each gene sequence using Primer3 software (Table 1.1; http://frodo.wi.mit.edu/cgi-bin/primer3/primer3_www.cgi). Quantitative PCR was performed in duplicate for each cDNA sample on a Bio-Rad iCycler iQ Real-Time PCR Detection System using iQTM SYBR1 Green Supermix (BioRad, Hercules, CA) in $25-\mathrm{ml}$ reaction volumes containing $300 \mathrm{nM}$ of each primer and 2 $\mu l$ diluted cDNA. Standard curves for each gene and the control were constructed using 10-fold serial dilutions of cDNA from reverse transcription of primers yielding a larger product $(\approx 350 \mathrm{bp})$ than cDNA from samples $(\approx 150 \mathrm{bp})$. Threshold lines were adjusted to intersect amplification lines in the linear portion of the amplification curve and cycles to threshold $(\mathrm{Ct})$ were recorded. For each sample, the quantities of mRNA for the genes of interest and the control gene (GAPDH) were determined from the appropriate standard curves. The quantity of each mRNA was then divided by the quantity of mRNA for GAPDH to obtain a normalized value.

Incubation of Luteal Cells. Dispersed luteal cells were obtained as described by Milvae et al. (1986). For analysis of net biosynthesis of progesterone, 1 X $10^{5}$ cells were incubated in quadruplicate with treatments for $2 \mathrm{~h}$ and frozen at the end of incubation. Treatments included: control, 5 ng bovine LH (USDA bLH B-5, USDA Animal Hormone Program, Beltsville, MD), $1 \mu \mathrm{g}$ arachidonic acid (AA; Sigma Chemical Co., St. Louis, MO), $10^{-10}$ to $10^{-7} \mathrm{M}$ endothelin-1 (ET-1; Sigma Chemical Co., St. Louis, MO), and combinations of each dosage of ET-1 with LH or AA. One set of quadruplicate tubes for each CL was frozen immediately after cell dispersion for determination of pre-incubation 
concentrations of progesterone. Data were analyzed and reported as net biosynthesis (progesterone after $2 \mathrm{~h}$ culture - progesterone pre-incubation). For analysis of synthesis of $\mathrm{PGF}_{2} \alpha$ and 6-keto-PGF $1 \alpha, 1 \times 10^{6}$ cells were incubated in duplicate with treatments for 2 $\mathrm{h}$ and frozen at the end of incubation. Treatments included: control, $1 \mu \mathrm{g} \mathrm{AA}, 10^{-10}$ to $10^{-}$ ${ }^{7}$ M ET-1, and combinations of each dosage of ET-1 with AA. One set of quadruplicate tubes for each CL was frozen immediately after cell dispersion for determination of preincubation concentrations of each PG. Data were analyzed and reported as the difference between pre- and post-incubation values for each PG.

Assays for Progesterone, PGF2 $\alpha$, and 6-keto-PGF1 $\alpha$. Luteal and serum concentrations of progesterone were determined by radioimmunoassay as described by Sheffel et al. (1982). The inter- and intra-assay coefficients of variation were $7.1 \%$ and $5.5 \%$, and sensitivity was $0.12 \mathrm{ng} / \mathrm{mL}$. Luteal tissue was homogenized in $1 \mathrm{~mL}$ phosphate buffered saline per mg tissue. The homogenate was centrifuged at 1,500 $\mathrm{g}$ for $15 \mathrm{~min}$., the supernatant was diluted 1 to 800 in PBS, and $100 \mu$ diluted supernatant was used in the progesterone assay. Frozen serum was allowed to thaw at $4^{\circ} \mathrm{C}$ and $100 \mu 1$ was used in the progesterone assay. Concentrations of progesterone, $\mathrm{PGF}_{2} \alpha$, and 6-keto- $\mathrm{PGF}_{1} \alpha$ from incubation of luteal cells were determined by radioimmunoassays (Beal et al., 1980 and Milvae and Hansel, 1980, 1983; respectively). The inter- and intra-assay coefficients of variation were: progesterone $=8.4 \%$ and $9.3 \% ; \mathrm{PGF}_{2} \alpha=9.8 \%$ and $10.4 \%$; and 6-keto$\mathrm{PGF}_{1} \alpha=11.1 \%$ and $9.7 \%$.

Statistical Analysis. All data were distributed normally (Shapiro and Wilk, 1965). Total luteal progesterone, luteal progesterone concentration, and luteal concentration of mRNA were examined for relationship to progesterone in serum at $\mathrm{h} 0$ by linear 
regression with h 0 concentrations of progesterone in serum. Data for progesterone, $\mathrm{PGF}_{2} \alpha$, and 6-keto- $\mathrm{PGF}_{1} \alpha$ were examined by analysis of variance, using pre-incubation concentrations as covariates, for effects of classification of the cow based upon concentration of progesterone in serum at h 0 above or below the overall mean (High or Low, respectively), treatments during incubation and interaction of classification and treatment. Each breed was represented in both classes: High, $\mathrm{n}=3$ Ayrshire, 3 Holstein; Low, $\mathrm{n}=2$ Ayrshire, 4 Holstein. Fogwell et al. (1978) demonstrated that concentrations of progesterone in serum decreased approximately $80 \%$ during the first hour, and reached their lowest concentration by $6 \mathrm{~h}$, after removal of the CL from heifers. Therefore, $\mathrm{h} 0$ values were not included for examination of serum progesterone after lutectomy so that the biological response to exogenous progesterone would not be biased by the initial endogenous progesterone. Patterns of progesterone in serum were compared by analysis of variance with progesterone at h 0 (High vs. Low) in the main plot and time by classification in the sub-plot. Areas under the curve for serum progesterone after lutectomy were compared with concentration of progesterone at $\mathrm{h} 0$ as a covariate. Analyses were performed by the SAS ${ }^{\circledR}$ software (SAS Institute; Cary, NC).

\section{Results}

\section{Luteal Progesterone and Gene Expression}

Size of the $\mathrm{CL}$ at ultrasound $($ mean $=22.4 \mathrm{~mm})$ and luteal wet weight $($ mean $=$ $8.55 \mathrm{~g})$ were similar for each treatment. Total luteal progesterone content $($ mean $=106.0$ $\pm 3.3 \mu \mathrm{g}$ ) and concentration (mean $=12.7 \pm 0.5 \mu \mathrm{g} / \mathrm{g}$ ) did not differ between High and Low cows (Figure 1.1) and neither was associated with h 0 concentrations of progesterone in serum $(b=0.36$ and 0.11 , respectively). Total luteal progesterone was not 
associated with luteal wet weight or size at ultrasonography $(b=0.24)$. Luteal contents of mRNA for enzymes from the endothelin and prostaglandin pathways were not associated with h0 progesterone and did not differ between classes (Figures 1.2 and 1.3, respectively).

\section{Luteal Cell Incubation}

Hour 0 progesterone and net progesterone biosynthesis during $2 \mathrm{~h}$ incubation without treatment (control) did not differ for luteal cells from High and Low cows (Figure 1.5a). Incubation with $5 \mathrm{ng}$ bovine $\mathrm{LH}$ increased $(\mathrm{P}<0.05)$ net biosynthesis of progesterone above control with no difference between classes (Figure 1.5a). Incubation with $1 \mu \mathrm{g}$ AA alone did not alter biosynthesis of progesterone (Figure 1.5a). Both basal and LH-stimulated secretion of progesterone from luteal cells were inhibited by ET-1 in a dose-dependent manner ( $\mathrm{P}<0.0001$; Figures $1.5 \mathrm{~b}$ and $\mathrm{c}$, respectively). A class effect was detected when ET-1 was added in the presence of AA; in that situation, reduction of progesterone production by ET-1 was greater $(\mathrm{P}<0.05)$ for luteal cells of Low cows (Figure 1.5d).

Initial, control, and AA-stimulated concentrations of $\mathrm{PGF}_{2} \alpha$ (Figure 1.6a) and 6keto-PGF $1 \alpha$ (Figure 1.7a) did not differ for luteal cells from High and Low cows. Concentrations of $\mathrm{PGF}_{2} \alpha$ were increased $(\mathrm{P}<0.0001)$ in a dose-dependent manner by addition of ET-1 or ET-1 and AA to incubation media with no difference between classes (Figures $1.6 \mathrm{~b}$ and c, respectively). In contrast, concentrations of 6-keto- $\mathrm{PGF}_{1} \alpha$ were decreased $(\mathrm{P}<0.0001)$ in a dose-dependent manner by addition of ET-1 or ET-1 and AA to incubation media, and again, there was no difference between High and Low cows (Figure $1.7 \mathrm{~b}$ and c, respectively). 


\section{Serum Progesterone Post-Lutectomy}

Patterns of concentrations of progesterone in serum after CL removal differed (P $<0.0001)$. Concentrations were greater and increased more after $36 \mathrm{~h}$ for cows in the High than in the Low group during twice-daily injections of exogenous progesterone (150 mg s.c.; Figure 1.4). Area under the curve for serum progesterone, not including h 0 values, ranged from 125 to 36 (mean $=66$ arbitrary units) for individual cows and differed between treatment groups $(\mathrm{P}=0.03)$ Area under the curve was correlated positively $(b=0.74 ; \mathrm{P}=0.006)$ with $\mathrm{h} 0$ progesterone in serum. Plasma concentrations of progesterone, either before or after lutectomy, were not associated with milk production.

\section{Discussion}

Luteal content and concentration of progesterone did not differ for cows with High versus Low circulating concentrations of progesterone. Stormshak et al. (1963) measured the association of luteal progesterone content and concentration with ovarian veinous drainage throughout the estrous cycle of ewes. They found that luteal progesterone content increased along with total luteal weight. Concentration of progesterone in ovarian effluent blood was correlated positively with total luteal content of progesterone. By sampling over time, they calculated secretory rate of luteal progesterone and demonstrated that total luteal progesterone content was indicative of luteal secretion of hormone into the blood (Stormshak et al., 1963). Gomes et al. (1963) found that jugular blood progesterone was not predictive of the quantity of progesterone in the CL of non-pregnant dairy cows during the estrous cycle. These reports demonstrate that luteal progesterone content at a single time point indicates luteal function more specifically than concentrations of progesterone in peripheral serum, and that was confirmed in the present study. 
Expression of mRNAs for genes involved in the endothelin and prostaglandin systems was similar for luteal tissue from High and Low cows. The mRNA for preproendothelin-3 was less abundant than preproendothelin- 1 and endothelin receptor-A was more abundant than endothelin receptor-B. These data correspond well with previous reports of relative expression of genes from the endothelin family in cow CL (Choudhary et al., 2004). Interestingly, the expression of aldoketoreductase 1B5 (AKR1B5), the prostaglandin $\mathrm{F}$ synthase (PGFS) considered important for synthesis of $\mathrm{PGF}_{2} \alpha$ in the cow CL during luteal regression (Arosh et al., 2004), was relatively low compared to other genes of the prostaglandin system measured in this experiment (Figure 1.3). Costine et al. (2007) reported that the expression of AKR1B5 was similar in the CL of pregnant and non-pregnant ewes before $\mathrm{PGF}_{2} \alpha$ injection on $\mathrm{d} 12$ post-estrus, but that its expression decreased in non-pregnant, but not in pregnant ewes $4 \mathrm{~h}$ after injection of $\mathrm{PGF}_{2} \alpha$. Abundance of AKR1B5 mRNA in CL of cows was greater on d 16 than $\mathrm{d} 5$ and greater in $\mathrm{d} 5$ short-lived CL than in d 5 normal CL (Costine, 2004). Arosh et al. (2004) found a shift in expression of AKR1B5 relative to expression of PGES that favored PGES in cow CL during $\mathrm{d} 10$ to 13 of the estrous cycle. The actual quantity that could be expected in $\mathrm{CL}$ of pregnant cows is not clear. However, the relatively low abundance reported here might be specific to CL of pregnancy and could indicate an important self-protective mechanism.

Endothelin-1, either alone or in combination with AA, decreased basal and LHstimulated progesterone production by dispersed luteal cells in a dose-dependent manner. This result corresponds with similar in vitro experiments conducted with luteal cells from the mid-luteal phase of the bovine estrous cycle (Girsh et al., 1996a; Sen et al., 2005; Sen 
et al., 2006). Moreover, luteal cells from Low cows incubated with ET-1 and AA produced less progesterone than luteal cells from High cows. Addition of AA to incubated luteal cells in culture increased secretion of anti-steroidogenic $\mathrm{PGF}_{2} \alpha$, which might have occurred by shifting the enzymatic conversion away from the luteotropic prostaglandin, $\mathrm{PGI}_{2}$, as indicated by decreased accumulation of its metabolite 6-keto$\mathrm{PGF}_{1} \alpha$ (Figures 1.6 and 1.7). However, there was no significant effect of class on stimulation of $\mathrm{PGF}_{2} \alpha$ or inhibition of $\mathrm{PGI}_{2}$ by ET-1.

Alternatively, luteal cells from Low cows might have less capacity to catabolize $\mathrm{PGF}_{2} \alpha$ into 13,14 dihydro 15-keto $\mathrm{PGF}_{2}$ (PGFM) compared to cows with high serum progesterone. Corpora lutea from pregnant ewes on d 14 had a greater capacity to catabolize $\mathrm{PGF}_{2} \alpha$ into PGFM than CL from non-pregnant ewes in spite of the fact that mRNA expression for PGDH did not differ (Costine et al., 2007). However, the hypothesis that increased PGDH activity is responsible for the class difference in progesterone in response to ET-1 and AA in this study was not supported because there was not a class difference in either mRNA for PGDH or luteal secretion of $\mathrm{PGF}_{2} \alpha$. The data presented here indicate that luteal secretion of progesterone, and the systems known to alter it, function similarly for cows with high and low peripheral serum concentrations of progesterone during gestation. Changes in factors that modulate luteal function throughout the estrous cycle do not appear to explain lower serum concentrations of progesterone in some pregnant cows around d 30 of gestation.

Concentrations of serum progesterone during replacement with a dosage of exogenous progesterone known to maintain pregnancy after lutectomy (Bridges et al., 2000; Starbuck et al., 2004) were greater for cows in the High than in the Low class. 
Earlier reports have indicated that steroid clearance differs with physiological status. For example, although ovulatory follicles and corpora lutea were smaller in heifers, circulating concentrations of progesterone and estradiol were greater in heifers than in lactating cows (Wiltbank et al., 2006). Luteal size and follicular diameter also were smaller for non-lactating versus lactating dairy cows without differences in serum concentrations of progesterone or estradiol (Sangsritavong et al., 2002). In their review, Wiltbank and coauthors (2006) calculated an "index of circulating progesterone concentration divided by luteal volume" and found that heifers had twice the calculated value of lactating cows. This ratio was related more closely to milk production than circulating steroid concentration (Wiltbank et al., 2006).

The effects of dry matter or energy intake on steroid metabolism have varied with method of investigation. By calculating energy balance as daily net energy intake minus net energy required for maintenance and lactation, Villa-Godoy et al. (1988) determined that milk progesterone was reduced by caloric deficit in lactating dairy cows. Moreover, the degree of this reduction was modulated by the timing and magnitude of maximal caloric deficit. In contrast, Sangsritavong et al. (2002) reported an acute increase in liver blood flow and metabolic clearance rate for infused progesterone and estradiol-17 $\beta$ in lactating and non-lactating dairy cows fed above maintenance. Rabiee et al. (2002c) found greater serum concentrations of progesterone for feed-restricted compared to ad libitum-fed, non-lactating, ovariectomized cows when exogenous progesterone was supplied by either 1 or 2 simultaneous CIDRs. Furthermore, concentrations of serum progesterone in non-lactating, ovariectomized cows receiving subcutaneous injections of $200 \mathrm{mg}$ progesterone daily and fed at 1/2-maintenance were greater than in similarly 
treated cows fed at maintenance (Rabiee et al., 2001c). However, serum, milk and fecal concentrations of progesterone, in lactating dairy cows treated with CIDRs, were not affected by intakes of dry matter and metabolizable energy (Rabiee et al., 2002b). The bulk of evidence indicates that increased dry matter and metabolizable energy intake is negatively associated with steroid metabolism. Whether this effect is solely the result of increased liver blood flow is yet to be determined. Greater feed intake decreased concentrations of progesterone in the serum of ewes during the estrus cycle (Parr et al., 1993; Kiyma et al, 2004), increased liver blood flow (Parr et al., 1993), and increased the concentration of mixed function oxidase enzymes in liver biopsies (Thomas et al., 1987). Smith et al. (2006) hypothesized that fatty acids could alter metabolism of progesterone by the liver. They showed a transient difference in serum concentrations of progesterone between acetate or propionate gavaged ewes receiving intramuscular injections of progesterone. However, their results were not confirmed by Lemley et al. (2007) who fed acetate or propionate and injected progesterone intravenously.

Indirect indicators of increased steroid metabolism for lactating dairy cows have been reported. Duration of estrus was reduced for cows producing above the herd average milk yield as compared to those producing below herd average (Lopez et al., 2004). Additionally, high-producing cows had a larger ovulatory follicle, but lower serum estradiol than low-producing cows. Fricke and Wiltbank (1999) reported that occurrence of double ovulation was 13 percentage points greater for cows with above average milk production compared to below average contemporaries. In a retrospective study, Lopez et al. (2005) demonstrated that development of multiple dominant follicles was associated with greater LH and FSH during the 24-h period prior to follicular selection. Circulating 
concentration of progesterone was lower for these cows, and the authors hypothesized that this decrease caused increased gonadotropin secretion, consistent with the data of Kinder et al. (1996) and Taft et al. (1996).

On the basis of the present data, clearance was a more important determinant of peripheral concentrations of progesterone than luteal production. This finding supports the hypothesis that low circulating concentrations of progesterone, known to affect fertility among lactating dairy cows, result from altered nutritional demands. It stands to reason that the factors controlling rate of steroid clearance for lactating dairy cows would remain similar during the estrous cycle and early to mid gestation. Dry matter and energy intake were not controlled or measured in this experiment. The fact that serum concentration of progesterone before and after lutectomy was not correlated with milk production in this study might reflect the degree of variation and the relatively small number of cows studied. However, the finding that injected progesterone supported greater circulating concentrations of progesterone in cows with greater serum progesterone prior to lutectomy compared to those with lower concentrations, is strong evidence that metabolic clearance is responsible for lower peripheral concentrations of progesterone in some cows. 
Table 1.1 Primer sequences and PCR conditions

\begin{tabular}{|c|c|c|c|c|c|}
\hline Gene & Primer Sequence & Accession number & $\begin{array}{l}\text { Product } \\
\text { Size }(\mathrm{bp})\end{array}$ & $\begin{array}{l}\text { Annealing } \\
\text { temperature } \\
\left({ }^{\circ} \mathrm{C}\right) \\
\end{array}$ & $\begin{array}{l}\text { Intra- } \\
\text { assay } \\
\mathrm{CV}^{\mathrm{a}} \\
\end{array}$ \\
\hline GAPDH & $\begin{array}{l}\text { Forward 5' AATATCATCCCTGCTTCTACTGG 3' } \\
\text { Reverse 5' CATACTTGGCAGGTTTCTCCA 3' }\end{array}$ & gi:77404272 & 154 & 57 & $6.1^{b}$ \\
\hline Cyclooxygenase-2 & $\begin{array}{l}\text { Forward 5' ATGTATCCTCCCACTGTCAAAG 3' } \\
\text { Reverse 5' TGTTCCCGCAGCCAAATG 3' }\end{array}$ & gi:1703495 & 146 & 53 & 10.1 \\
\hline Aldoketoreductase 1B5 & $\begin{array}{l}\text { Forward 5' AAGTGGTGAAGCCTGAGG 3' } \\
\text { Reverse 5' CAGTGGATGAGGTAGAGGTC 3' }\end{array}$ & gi:265403 & 138 & 57 & 11.3 \\
\hline Prostaglandin 15-dehydrogenase & $\begin{array}{l}\text { Forward 5' ACCTACCTGGGCTTGGATTAC 3' } \\
\text { Reverse 5' CTGCCGAGCGTGTGAATC 3' }\end{array}$ & gi:4033852 & 150 & 64 & 9.3 \\
\hline Prostaglandin E synthase & $\begin{array}{l}\text { Forward 5' CAACTGAGGCTGCGGAAG 3' } \\
\text { Reverse 5' CCAGGAACAGGAAGGGGTAG 3' }\end{array}$ & gi:31341986 & 150 & 62 & 9.8 \\
\hline Preproendothelin-1 & $\begin{array}{l}\text { Forward 5' ATCATCTGGGTCAACACTCC 3' } \\
\text { Reverse 5' TAGCACACTGGCATCTCTTC 3' }\end{array}$ & gi:31341389 & 129 & 51 & 16.5 \\
\hline Preproendothelin-3 & $\begin{array}{l}\text { Forward 5' TGTGCCAGCGAGATGGTAT 3' } \\
\text { Reverse 5' GCCCTAAGGAACACAAGCTG 3' }\end{array}$ & gi:119905653 & 155 & 59 & 6.5 \\
\hline Endothelin converting enzyme-1 & $\begin{array}{l}\text { Forward 5' GCATCCAATACCAGACAAGAAC 3' } \\
\text { Reverse 5' ACAGGCATAGGTGAAGAAGTC 3' }\end{array}$ & gi:31341344 & 127 & 58 & 16.3 \\
\hline Endothelin receptor-A & $\begin{array}{l}\text { Forward 5' TGTCCTTCTGGGTGGCTCTG 3' } \\
\text { Reverse 5' TTCGTGGGTTGATGTGTGGTG 3' }\end{array}$ & gi:27805816 & 144 & 54 & 6.9 \\
\hline Endothelin receptor-B & $\begin{array}{l}\text { Forward 5' GCAGGATTTTGAAGCTCACTC 3' } \\
\text { Reverse 5' TTTTGCTCACCAAATACAGAGC 3' }\end{array}$ & gi:31342360 & 150 & 57 & 9.7 \\
\hline
\end{tabular}




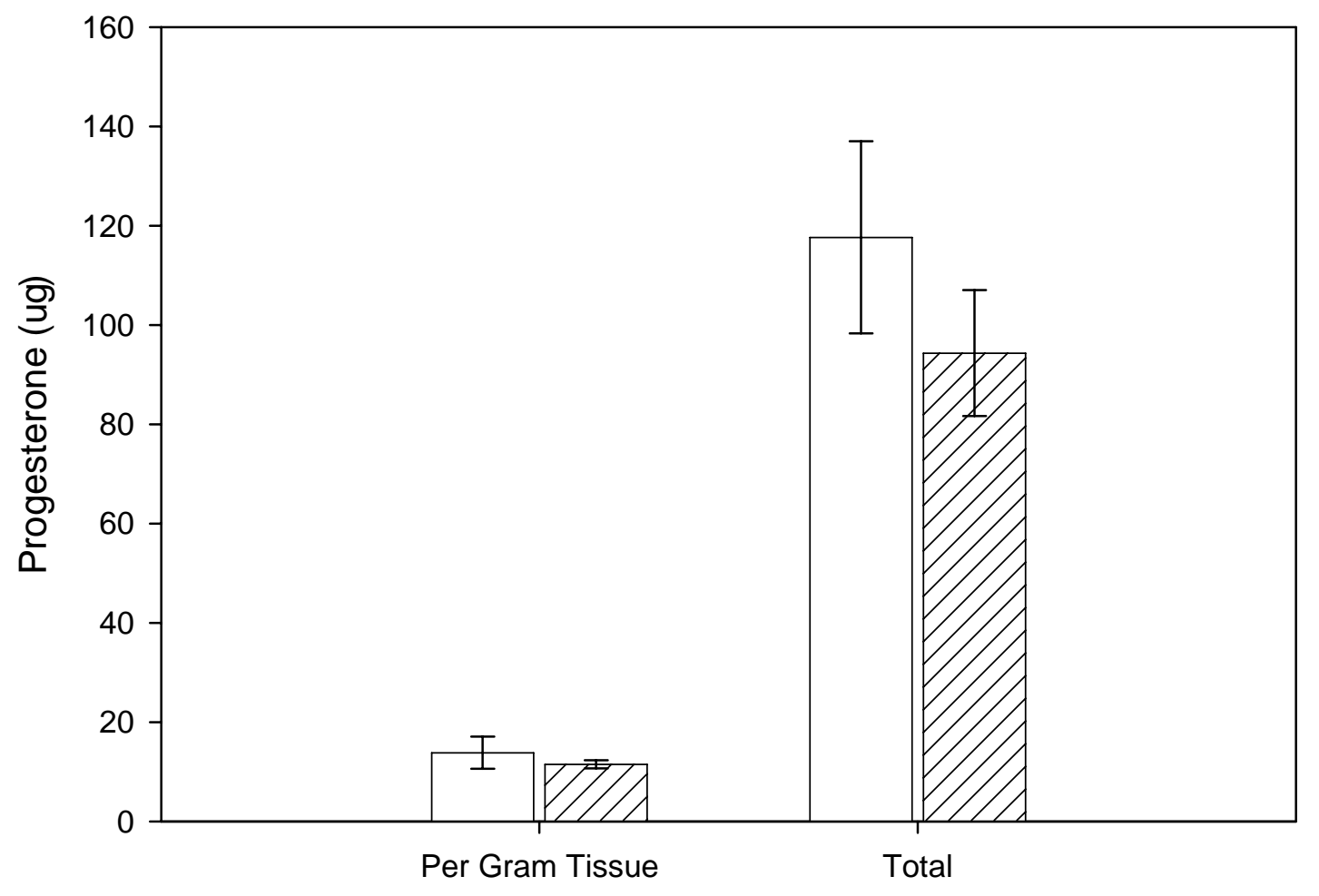

Figure 1.1 Luteal Progesterone

Luteal concentration ( $\mu \mathrm{g}$ / gram tissue) and content $(\mu \mathrm{g})$ of progesterone in CL of cows with High (open bars) or Low (hashed bars) circulating concentrations of progesterone. Means \pm SEM. 


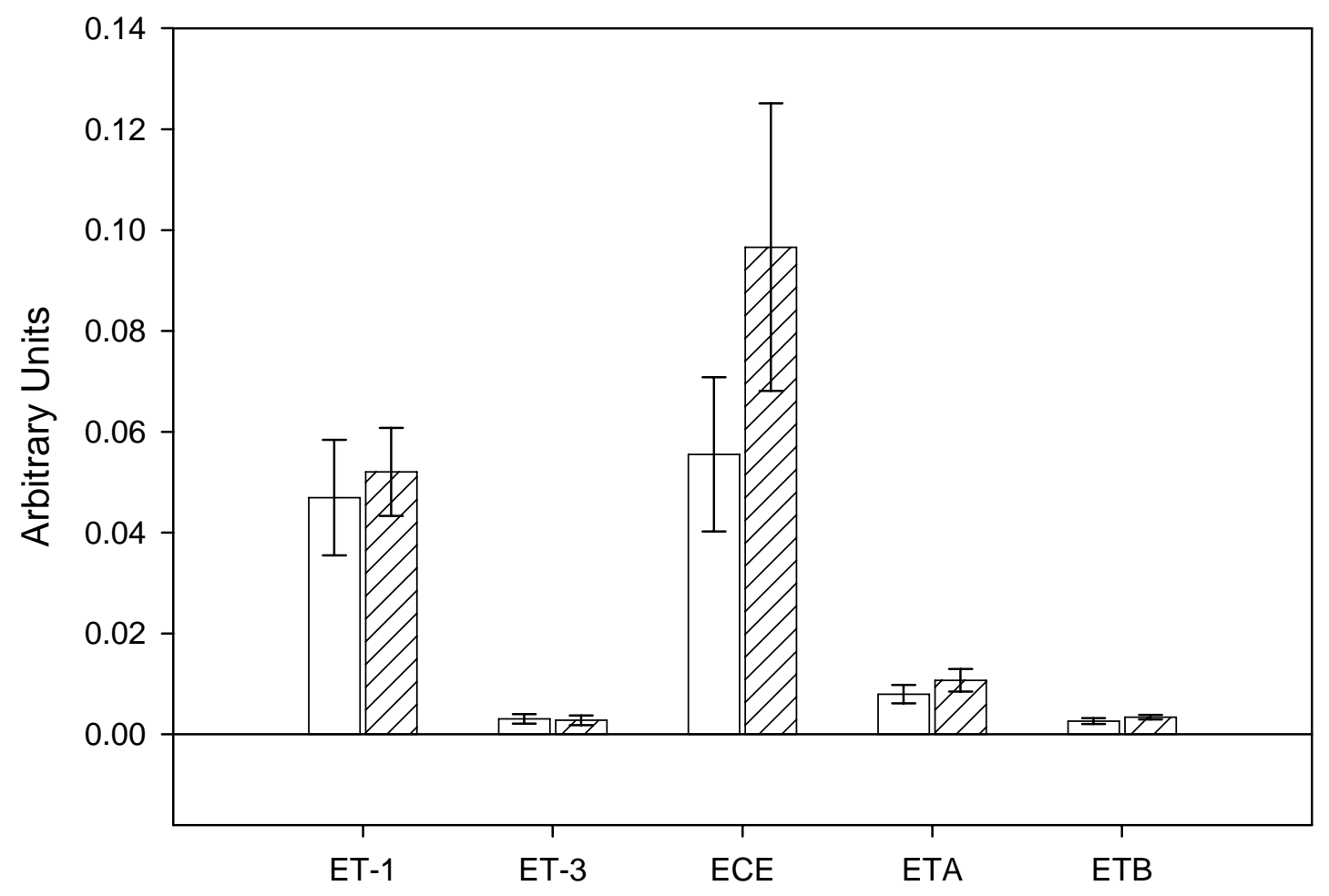

Figure 1.2 Endothelin Gene Expression

Abundance of mRNA for preproendothelin-1 (ET-1), preproendothelin-3 (ET-3), endothelin converting enzyme (ECE), endothelin receptor A (ET-A), and endothelin receptor B (ET-B) in CL of cows with High (open bars) or Low (hashed bars) circulating concentrations of progesterone. Means \pm SEM. 


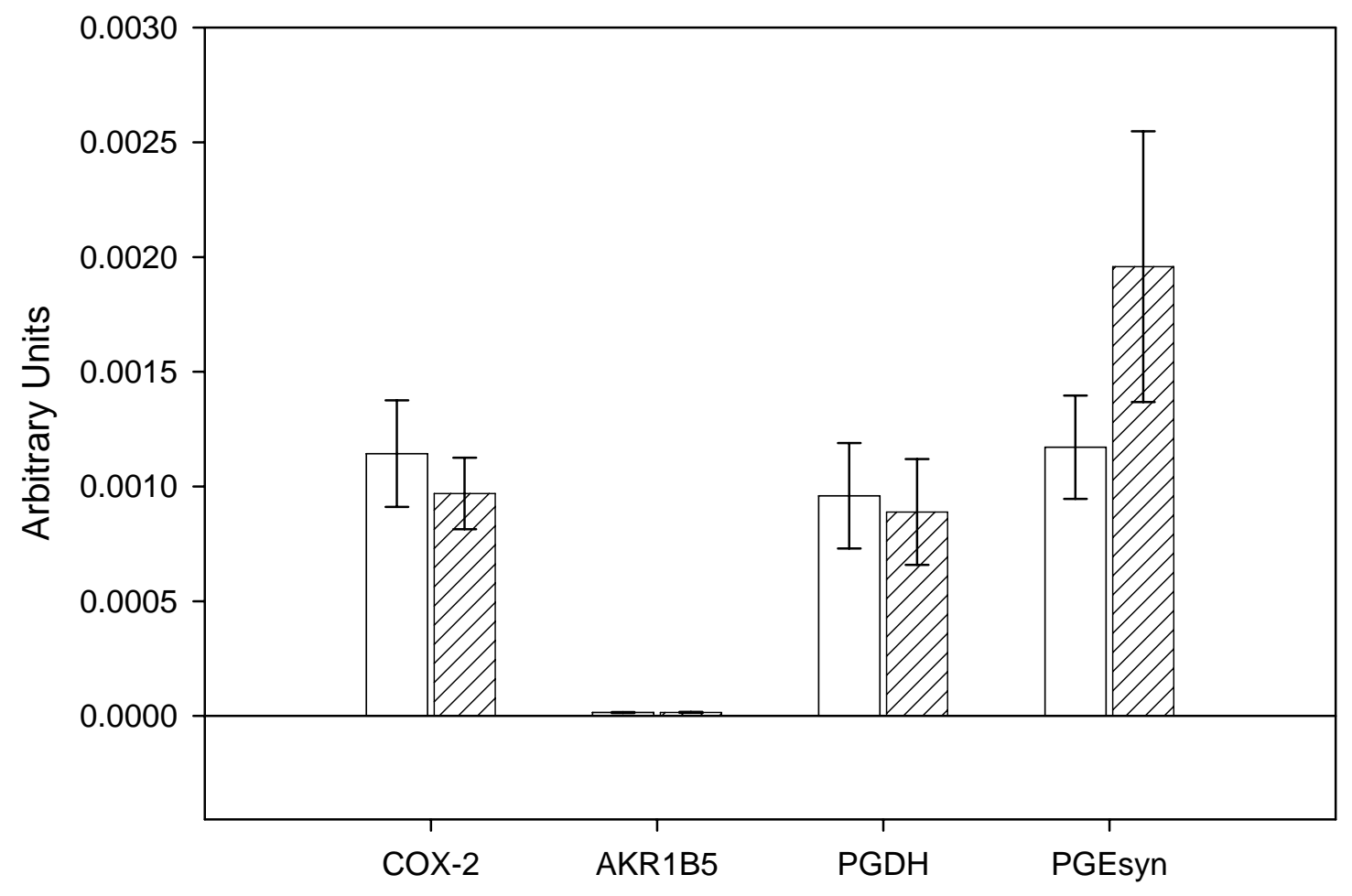

Figure 1.3 Prostaglandin Gene Expression

Abundance of mRNA for cyclooxygenase-2 (COX-2), aldoketoreductase 1B5

(AKR1B5), prostaglandin 15-dehydrogenase (PGDH), and prostaglandin E synthase (PGES) in CL of cows with High (open bars) or Low (hashed bars) circulating concentrations of progesterone. Means \pm SEM. 


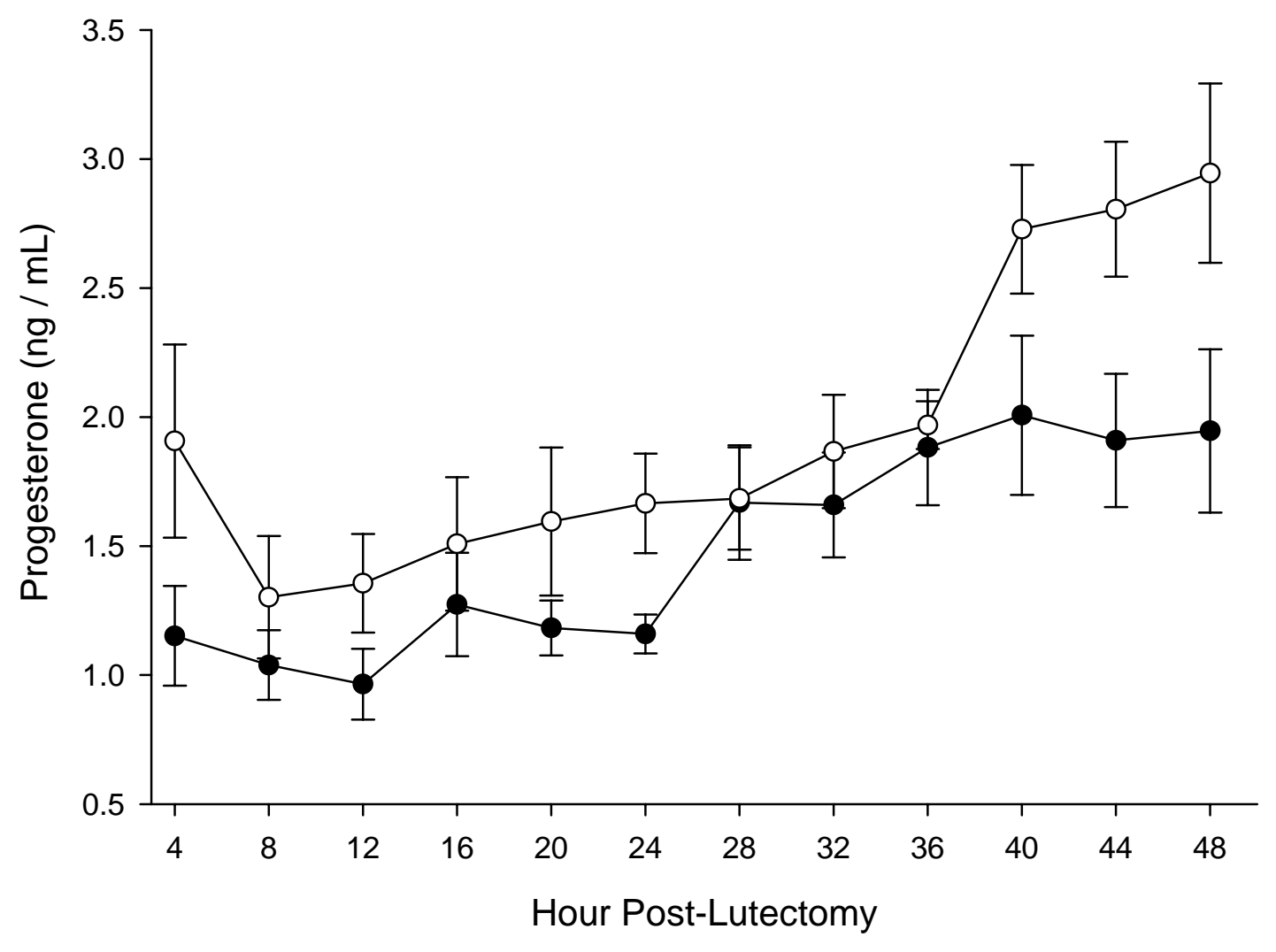

Figure 1.4 Post Lutectomy Serum Progesterone

Patterns of progesterone (ng / $\mathrm{mL}$ ) in serum, after lutectomy, for cows with High (open circles) or Low (filled circles) circulating concentrations of progesterone prior to lutectomy. Samples were taken every $4 \mathrm{~h}$ for $48 \mathrm{~h}$. Progesterone $(150 \mathrm{mg})$ was injected s.c. every $12 \mathrm{~h}$. Means \pm SEM. 

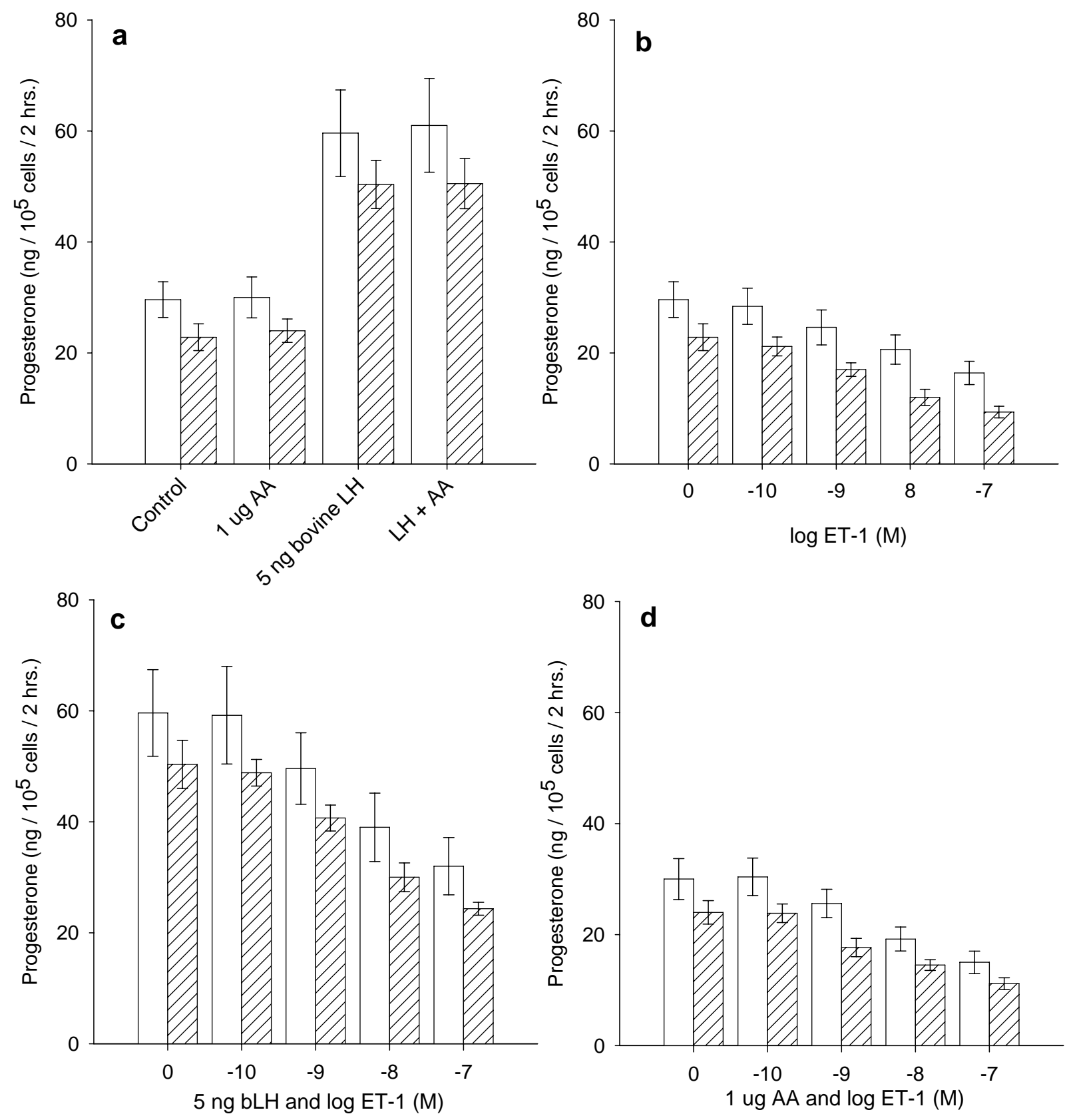

Figure 1.5 Luteal Cell Progesterone Production

Net biosynthesis of progesterone ( $\mathrm{ng} / 10^{5}$ cells / $2 \mathrm{~h}$ ) by dispersed luteal cells, from CL of cows with High (open bars) or Low (hashed bars) circulating concentrations of progesterone, incubated without treatment (a, Control) or with $1 \mu \mathrm{g}$ arachidonic acid (a, AA), 5 ng bovine luteinizing hormone (a, LH), LH and AA (a) increasing concentrations of endothelin-1 (b, $10^{-10} \mathrm{M}$ ET to $10^{-7} \mathrm{MET}$ ), or combinations of LH or AA and increasing concentrations of ET (c, ET $+\mathrm{LH}$ and d, ET $+\mathrm{AA}$; respectively). Means $\pm \mathrm{SEM}$. 

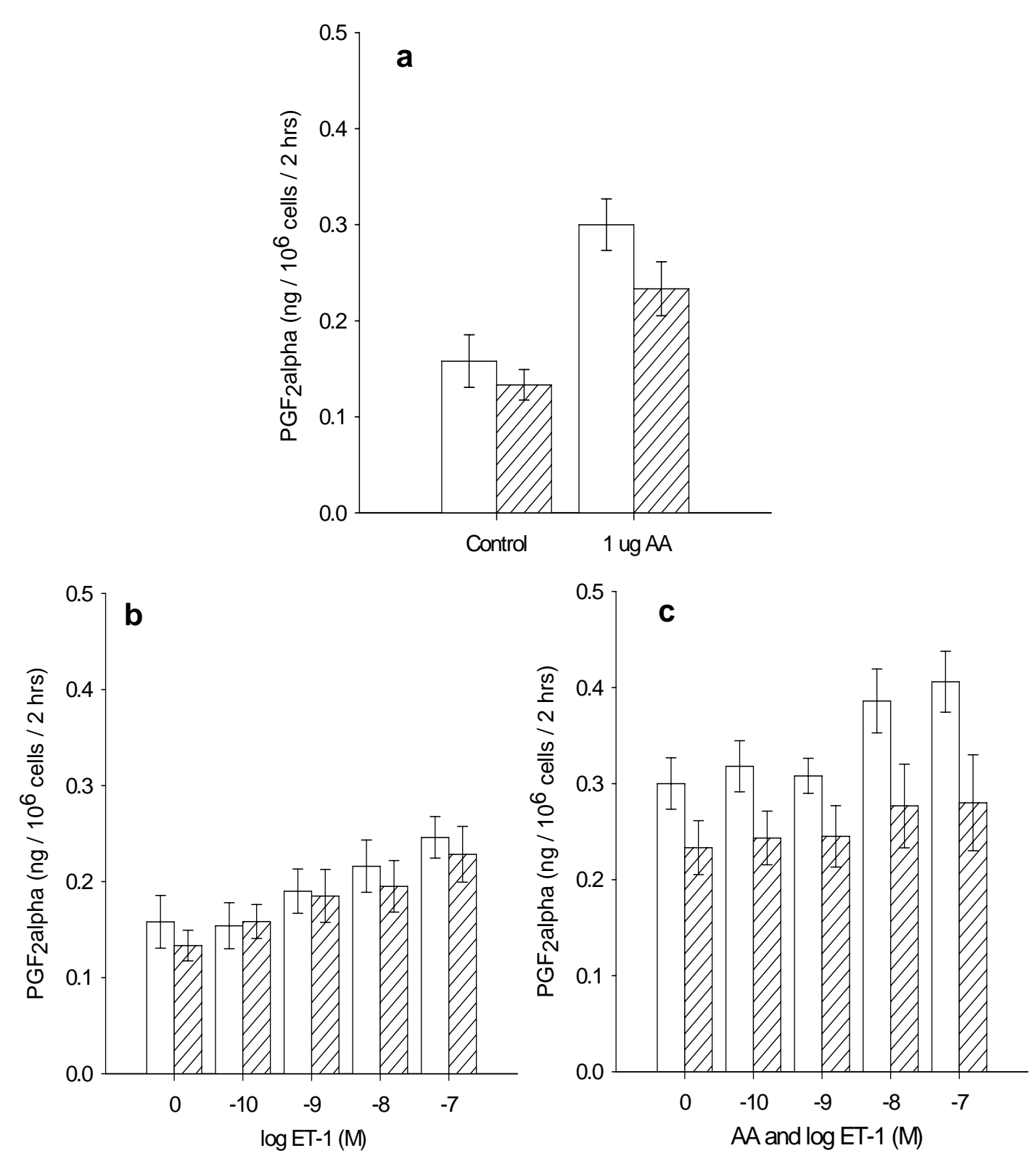

Figure 1.6 Luteal Cell $\mathrm{PGF}_{2} \alpha$ Production

Net production of prostaglandin $\mathrm{F}_{2} \alpha\left(\mathrm{PGF}_{2} \alpha ; \mathrm{ng} / 10^{6}\right.$ cells / $\left.2 \mathrm{~h}\right)$ by dispersed luteal cells, from CL of cows with High (open bars) or Low (hashed bars) circulating concentrations of progesterone, incubated without treatment ( $\mathrm{a}$, Control) or with $1 \mu \mathrm{g}$ arachidonic acid (a, AA), increasing concentrations of endothelin-1 (b, $10^{-10} \mathrm{MET}$ to $10^{-7} \mathrm{MET}$ ), or the combination of AA and increasing concentrations of ET (c, ET+AA). Means \pm SEM. 

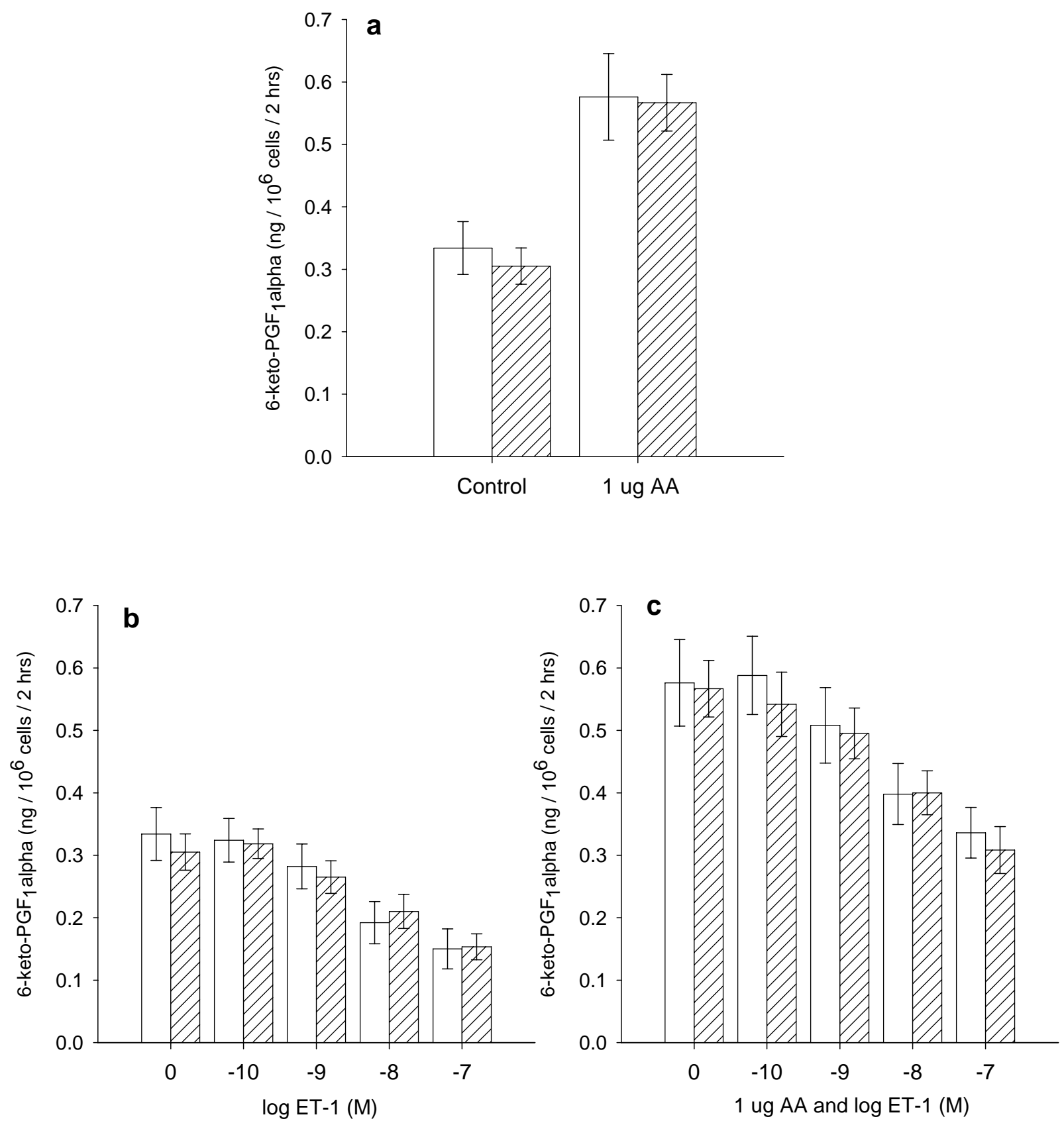

Figure 1.7 Luteal Cell 6-keto-PGF $1 \alpha$ Production

Net production of 6-keto-prostaglandin $\mathrm{F}_{1} \alpha$ (6-keto-PGF $1 \alpha$; ng / $10^{6}$ cells / 2 h) by dispersed luteal cells, from CL of cows with High (open bars) or Low (hashed bars) circulating concentrations of progesterone, incubated without treatment ( $\mathrm{a}, \mathrm{Control}$ ) or with $1 \mu \mathrm{g}$ arachidonic acid (a, AA), increasing concentrations of endothelin-1 (b, $10^{-10} \mathrm{M}$ ET to $10^{-7} \mathrm{MET}$ ), and combination of AA and increasing concentrations of ET (c, $\mathrm{ET}+\mathrm{AA})$. Means $\pm \mathrm{SEM}$. 


\section{ASSOCIATION OF TIMING OF CHORIOALLANTOIC MEMBRANE DEVELOPMENT WITH AGE IN DAIRY CATTLE}

\section{Abstract}

About $12 \%$ of lactating dairy cows experience late embryonic or early fetal death (d 30 to 60 of gestation). These losses are economically important because lengthened interestrous intervals lead to longer calving intervals. Abnormal growth of the allantois and timing of its fusion with the chorion have preceded high rates of late embryonic / early fetal loss of manipulated embryos. This study characterized timing of detection of the allantois and diameter of the allantoic lumen, in dairy cows and heifers with embryos developed entirely in vivo, to determine whether these variables might be used to investigate late embryonic / early fetal loss. Reproductive tracts of dairy heifers $(\mathrm{n}=33)$ and lactating dairy cows $(n=30)$ were examined daily, via transrectal ultrasonography (Aloka 900), beginning on d 21 post-insemination (PI). Variables included: first day of detection of the allantois, diameter of the allantoic lumen, length of the embryo at first detection of the allantois, and pregnancy retention on d 60 PI. Range and mean of first day of detection of the allantois $(\mathrm{d} 21$ to 26 , mean $=23 \pm 0.18 \mathrm{PI})$ agreed with previous reports. The allantois was detected earlier $(\mathrm{P}<0.05)$ in heifers $(22.4 \pm 0.2 \mathrm{~d})$ than in cows $(23.6 \pm 0.2 \mathrm{~d})$. Diameter of the allantoic lumen at first detection $(4.6 \pm 0.3 \mathrm{~mm}) \mathrm{did}$ not differ with day of detection and was not affected by age of dam. In contrast, length of embryo (range 2.6 to $7.9 \mathrm{~mm}$ ) varied with day of first detection of the allantois $(\mathrm{P}<$ 0.05), but not with age of dam. Pregnancy failure by day 60 PI did not differ with age of the dam. Differences in failure for pregnancies in which the allantois was detected earlier $(\leq \mathrm{d} 23 \mathrm{PI})$ or later $(\geq \mathrm{d} 24 \mathrm{PI})$ approached significance $(\mathrm{P}=0.08)$ with those detected earlier failing more frequently than those detected later. Differences in day of first 
ultrasonographic detection of placental membranes, between heifers and cows, might reflect differing developmental rates and, based on present data, asynchrony in development of the embryo and the placental membranes might occur in some animals. Therefore, day of detection of the allantois might be useful for predicting survival or loss of pregnancy during placentation and analysis of molecular characteristics of the developing allantois could help to identify mechanisms that compromise late embryonic / early fetal survival.

\section{Introduction}

Late embryonic / early fetal pregnancy failure (d 25 to 60 of gestation) in dairy cows leads to lengthened interestrous intervals and more days in milk before a successful pregnancy is established. The frequency of pregnancy loss during this period of gestation has been reviewed thoroughly (Kummerfield et al., 1978; Sreenan and Diskin, 1986;

Dailey et al., 2002; Inskeep 2004; Inskeep and Dailey, 2005; and Diskin et al., 2006). Estimates ranged from 7 to $25 \%$ and are generally considered to occur at an approximate rate of $12 \%$.

Abnormal development of the allantois has been reported in situations associated with very high pregnancy loss for in vitro-produced embryos and somatic-cell-nucleartransfer, cloned pregnancies (Thompson and Peterson, 2000, Piedrahita et al., 2002). However, association of pregnancy survival or loss with allantoic development is not known for embryos developed entirely in vivo. When genetic aberrations that lead to poor allantoic development are elucidated, their patterns of expression can be compared in pregnancies derived by artificial insemination that are more likely to either succeed or fail during placentation. However, at this time, methods to determine the pattern of 
allantoic development without termination of the pregnancy have not been reported. This type of investigation might be facilitated by using ultrasonography to evaluate allantoic development.

Transrectal ultrasonography has been used successfully to determine the first day of appearance of the allantois in cows and heifers. On average, the allantois was first detected on day 23 post-insemination (PI) by Curran and colleagues (1986b) and by Boyd et al. (1988). Parity of the dam affected the timing of detection of the allantois by Kolour et al. (2005). They first observed the allantois on days 22, 23 and 26 in heifers,

primiparous and multiparous cows, respectively. The first day of detection of the allantois was similar for heifers and primiparous cows and each was statistically different than multiparous cows.

Development of the allantois can influence pregnancy maintenance during placentation and can be monitored by transrectal ultrasonography in cows and heifers. Furthermore, the range of days PI that the allantois is first detected by ultrasound, and evidence that age of the dam affects this timing, indicate inherent variability in allantoic development that might be associated with its ability to supply adequate vasculature to the placenta. Therefore, the objective of this study was to characterize the timing of detection of the allantois and diameter of the allantoic lumen, in dairy cows and heifers, to determine whether these variables might be used to investigate effects on late embryonic / early fetal loss.

\section{Materials and Methods}

Beginning on d $21 \mathrm{PI}$, the reproductive tracts of 33 nulliparous heifers and 30 parous cows (Holstein and Ayrshire) were examined daily with a real-time, B-mode 
ultrasound console equipped with a linear array, 7.5 MHz transducer (ALOKA SSD-900; Aloka Co., Ltd.; Tokyo, Japan). Day 0 was designated as the day of insemination. The first day of detection of the allantois, diameter of the allantoic lumen, length of the embryo proper at first detection of the allantois, and pregnancy retention on $\mathrm{d} 60$ PI were recorded. Detection of the allantois occurred when a circular line of echo-producing tissue appeared in the uterine lumen, sharing a field of view with the embryo (Fig. 2.1). All anatomical measurements were taken with electronic calipers at the time of ultrasonography. Diameter of the allantoic lumen was recorded as the average of the vertical and horizontal inside diameters at the widest point sharing a field of view with the embryo proper. Statistical analyses were performed by the SAS ${ }^{\circledR}$ software (SAS Institute; Cary, NC). Analysis of variance was used to examine the effect of age on day of detection of the allantois, diameter of the allantois, and length of the embryo proper. Linear regression was used to examine association of length of the embryo or diameter of the allantoic lumen with day the allantois was detected for cows and heifers combined. Differences in pregnancy retention on d 60 PI between cows and heifers and between pregnancies for which the allantois was detected early $(\leq \mathrm{d} 23 \mathrm{PI})$ or late $(\geq \mathrm{d} 24 \mathrm{PI})$ were examined by Chi square frequency analysis.

\section{Results}

Range and mean of first day of detection of the allantois (d 21 to 26, $23 \pm 0.18 \mathrm{PI}$ ) agreed with previous reports (Curran et al., 1986, Boyd et al., 1988 and Kolour et al., 2005) and were compatible with descriptions of embryonic gross anatomical development (Greenstein et al., 1958). The allantois was detected earlier $(\mathrm{P}<0.05)$ in heifers $(22.4 \pm 0.2 \mathrm{~d})$ than in cows $(23.6 \pm 0.2 \mathrm{~d})$. Diameter of the allantoic lumen at first 
detection $(4.6 \pm 0.31 \mathrm{~mm})$ did not differ with day of detection and was not affected by age of dam (Table 2.1). In contrast, length of embryo (range 2.6 to $7.9 \mathrm{~mm}$ ) increased $0.37 \mathrm{~mm}$ with each additional day to first detection of the allantois $(\mathrm{b}=0.37, \mathrm{P}<0.05)$, but was not affected by age of dam. Overall pregnancy loss by d 60 PI averaged $11 \%$ ( 7 of 63) and did not differ with age of the dam (cows $=3$ of 30; heifers $=4$ of 33). The difference in pregnancy loss by d 60 PI between pregnancies for which the allantois expanded earlier ( $\leq \mathrm{d} 23 \mathrm{PI} ; 16 \%, 7$ of 45$)$ and those for which the allantois expanded later ( $\geq \mathrm{d} 24 \mathrm{PI} ; 0 \%, 0$ of 18$)$ approached significance $(\mathrm{P}=0.08)$.

\section{Discussion}

The first day of detection of the allantois was earlier for heifers than cows. Kolour and coworkers (2005) also imaged the allantois earlier in heifers and primiparous cows than in multiparous cows. They postulated that earlier detection in heifers and primiparous cows was easier because of the relatively small size of the uterus (not quantified). However, that hypothesis excludes the possibility that extraembryonic membranes develop sooner for embryos in younger dams. In the present data, regardless of age, size of its lumen was not associated with earlier detection of the allantois. This might indicate that, because the younger allantois was not smaller at first detection, earlier detection is a function of more rapid embryonic development for pregnancies gestated in younger dams.

Differences in concentration of serum progesterone affect early embryonic development. Administration of progesterone to ewes early after estrus $(\mathrm{d} 0-3)$ advanced the development of the uterus such that, on $\mathrm{d} 6$ after estrus, it provided a suitable environment for continued development of a d 10 embryo (Lawson and Cahill, 
1983 and Vincent et al., 1986) but not for a d 6 embryo. Administration of supplemental progesterone during $\mathrm{d} 1$ to 4 and 5 to 9 post-insemination increased length of trophoblast on d 14 and 16 in cyclic beef and lactating dairy cows (Garrett et al., 1988 and Mann et al., 2006; respectively). Embryonic development was retarded on d 16 in non-lactating dairy cows with a delayed increase in serum progesterone compared to those that reached a concentration of $1 \mathrm{ng} / \mathrm{mL}$ by d 4 post-insemination (Mann and Lamming, 2006). The mediator for the effect of advanced embryonic development by increased progesterone concentration is likely histotrophic support from the uterine endometrium. Satterfield et al. (2006) demonstrated that augmenting serum concentrations of progesterone beginning $36 \mathrm{~h}$ after mating through d 9 or 12 increased the rate of blastocyst development and the concentration of uterine histotroph in ewes. The tendency for pregnancy failure to occur more frequently for pregnancies in which the allantois developed early might be explained by a discrepancy in the timing of attachment. If the conceptus begins attachment before the uterine endometrium is prepared to accept it, placentation could fail. The fact that the allantois was detected earlier in heifers than cows while pregnancy failure did not differ with age, might either be due to a wider window of uterine receptivity for heifers or simply an inadequate sample size to test this variable.

Regardless of age of dam, length of the embryo continued to increase with each additional day to detection of the allantois, despite the fact that the allantois was similar in size regardless of the day that it was detected. This might indicate that some pregnancies exhibit an asynchrony in development of the embryo and placental membranes. None of the studies reviewed here, using transrectal ultrasonography to characterize embryonic development, noted a relationship between the size of the 
allantois and length of the embryo. Maddox-Hyttel et al. (2003) examined seven embryos collected from two superovulated heifers slaughtered $21 \mathrm{~d}$ PI. Length of the embryo ranged from 3.14 to $5.79 \mathrm{~mm}$ while the allantois ranged in width from 1.15 to $4.41 \mathrm{~mm}$. The authors noted "a clear relationship between the embryo length and width of the allantois," but provided no statistical analysis to support the comment. The allantois had not yet developed for two embryos that were 3.14 and $3.77 \mathrm{~mm}$ long (Maddox-Hyttel et al., 2003).

Placental development was altered for embryos derived by assisted reproductive technologies such as in vitro fertilization (IVF) and somatic-cell-nuclear-transfer (SCNT) cloning. In fact, a majority of the embryonic mortality between days 30 and 60 of gestation for IVF- and SCNT-derived pregnancies was attributed to improper development of the allantois (Hill et al., 2000). Using serial slaughter of recipient cows that received an IVF embryo or were inseminated artificially, it was determined that the degree of malformation of the allantois ranged from aplasia to normal growth and vascularization without haematopoesis (Piedrahita et al., 2002). Furthermore, size of the follicle donating an oocyte for IVF affected placental development of the resulting embryo (Piedrahita et al., 2002). The length and width of the allantois on day 27 of gestation were smaller for embryos derived from small follicles. However, length and width of the embryo proper or the degree of vascularization of the allantois did not differ in relation to follicular size. In addition to differences in growth rate of the allantois, these authors reported a difference in the ability of the allantois to fuse with the chorion. For all 17 conceptuses derived from small follicles, the allantois and chorion detached during collection. In contrast, 14 of 18 conceptuses derived from large follicles presented 
fully fused chorioallantoic membranes that could not be detached manually after collection (Piedrahita et al., 2002). These findings hold particular interest in relation to the reports of increased embryonic loss for cows bred to ovulation of immature (Perry et al., 2005) and persistent (Ahmad et al., 1995) follicles.

Whether the degree of allantoic or chorionic vascularization could be assessed by color Doppler ultrasound is yet to be determined. However, if growth characteristics of the allantois, as determined by transrectal ultrasonography, are indicative of other distinct functions of allantoic development, it might prove to be a beneficial tool for investigating pregnancy failure during placentation. Monitoring the development of embryos derived by IVF and SCNT cloning by ultrasound could provide a means to determine these characteristics without terminating the pregnancy and allow testing for an association of the eventual sustainability of that specific conceptus with the developmental traits. It might also provide a method to select tissues that exhibit an abnormal growth pattern for molecular investigations.

Several genes have been identified as differentially expressed during allantoic emergence in bovine and ovine conceptuses (Ledgard et al., 2006). These authors used suppressive subtractive hybridization to compare mRNA expression in preimplantation conceptuses prior to emergence of the allantois and in allantoic samples after emergence. Nine genes were identified as differentially expressed. All were associated with extracellular matrix and vasculogenesis. Similarly, Ushizawa et al. (2004) used microarray analysis of cDNA to determine gene expression profiles in the bovine embryo during the preattachment period. They found differential expression of more than 1,000 genes on days 7, 14, 21 and 28. Comparison of extra-embryonic membranes and the 
embryo proper on day 28 reveled 119 down-regulated genes and 74 up-regulated genes in the membranes. The up-regulated genes included placental lactogen, prolactin-related proteins, pregnancy-associated glycoproteins and major histocompatibility complex molecules.

Collectively, results reported here illustrate that earlier ultrasonographic detection of the allantois in heifers than cows might represent an increased rate of embryonic development rather than detection of smaller structures. The relatively wide range for first day of detection of the allantois indicates that the factors controlling its development might be influenced by differing physiological states associated with age or lactational status. One factor that could mediate the effects of age and lactation on allantois development is concentration of serum progesterone. Low circulating concentrations of progesterone before breeding, during the first several days post-estrus, and during placentation have been identified as causes of embryonic loss during and after these respective periods and occur frequently in lactating dairy cows. Moreover, the use of transrectal ultrasonography to monitor development of the allantois between days 21 and 26 post-insemination could prove to be a valuable tool for investigating pregnancy failure at placentation. 
Table 2.1 Allantois Results Relative to Age of Dam

\begin{tabular}{llll}
\hline Age & Day of Detection & Diameter of Allantois & Length of Embryo \\
\hline \hline Heifer & $22.4 \pm 0.2^{\mathrm{a}}$ & $4.79 \pm 0.43 \mathrm{~mm}^{\mathrm{a}}$ & $4.96 \pm 0.27 \mathrm{~mm}^{\mathrm{a}}$ \\
Cow & $23.6 \pm 0.3^{\mathrm{b}}$ & $4.23 \pm 0.49 \mathrm{~mm}^{\mathrm{a}}$ & $4.75 \pm 0.23 \mathrm{~mm}^{\mathrm{a}}$ \\
\hline
\end{tabular}

Differing superscripts within columns indicate significance at $\mathrm{P}<0.05$. 


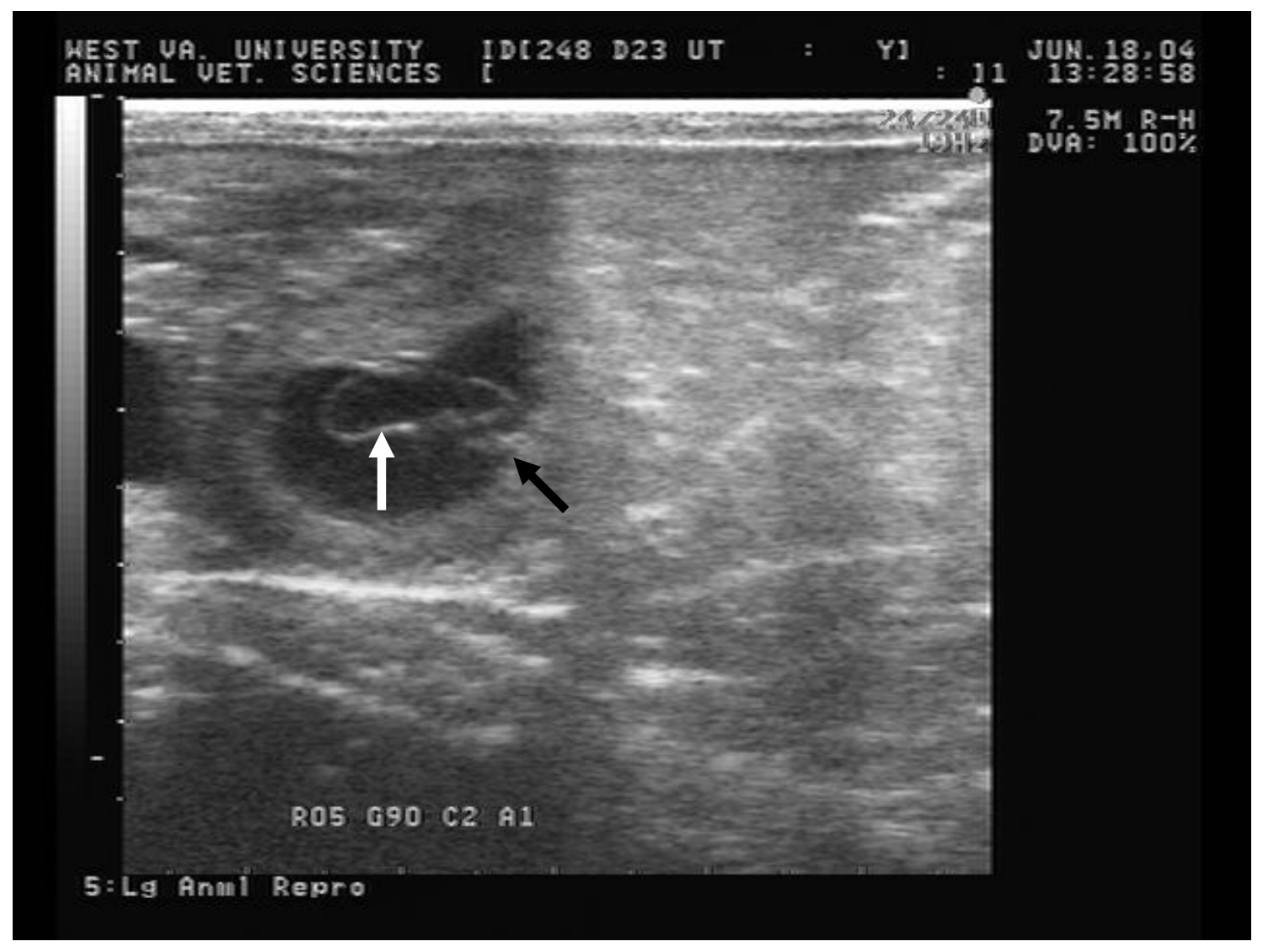

Figure 2.1 Representative Ultrasonographic Image

Representative image of the allantois (white arrow) and embryo proper (black arrow) on the first day of detection of the allantois at d 23 PI. 


\section{LITERATURE CITED}

Ahmad, N., F. N. Schrick, R. L. Butcher, and E. K. Inskeep. 1995. Effect of persistent follicles on early embryonic losses in beef cows. Biol Reprod 52: 1129-1135.

Arosh, J. A., S. K. Banu, P. Chapdelaine, E. Madore, J. Sirois, and M. A. Fortier. 2004. Prostaglandin biosynthesis, transport, and signaling in corpus luteum: A basis for autoregulation of luteal function. Endocrinology 145: 2551-2560.

Austin, E. J., M. Mihm, M. P. Ryan, D. H. Williams, and J. F. Roche. 1999. Effect of duration of dominance of the ovulatory follicle on onset of estrus and fertility in heifers. J Anim Sci 77: 2219-2226.

Ayalon, N. 1978. A review of embryonic mortality in cattle. J Reprod Fertil 54: 483-493.

Bazer, F. W. 1998. Allantois. Vol. 1, Pages 95-96 in Encyclopedia of reproduction. E. Knobil and J. D. Neill, eds. Academic Press, San Diego, CA.

Beal, W. E., R. A. Milvae, and W. Hansel. 1980. Oestrous cycle length and plasma progesterone concentrations following administration of prostaglandin $\mathrm{F}_{2} \alpha$ early in the bovine oestrous cycle. J Reprod Fertil 59: 393-396.

Belaoussoff, M., S. M. Farrington, and M. H. Baron. 1998. Hematopoietic induction and respecification of A-P identity by visceral endoderm signaling in the mouse embryo. Development 125: 5009-5018.

Boyd, J. S., S. N. Omran, and T. R. Ayliffe. 1988. Use of a high frequency transducer with real time B-mode ultrasound scanning to identify early pregnancy in cows. Vet Rec 123: 8-11.

Bridges, P. J., D. J. Wright, W. I. Buford, N. Ahmad, H. Hernandez-Fonseca, M. L. McCormick, F. N. Schrick, R. A. Dailey, P. E. Lewis, and E. K. Inskeep. 2000. Ability of induced corpora lutea to maintain pregnancy in beef cows. J Anim Sci 78: 2942-2949.

Breuel, K. F., P. E. Lewis, F. N. Schrick, A. W. Lishman, E. K. Inskeep and R. L. Butcher. 1993. Factors affecting fertility in the postpartum cow: role of the oocyte and follicle in conception rate. Biol Reprod 48(3): 655-661. 
Bulman, D. C., and G. E. Lamming. 1979. The use of milk progesterone analysis in the study of oestrus detection, herd fertility and embryonic mortality in dairy cows. Br Vet J 135: 559-567.

Casida, L. E. 1959. Research techniques in physiology of reproduction in the female. Pages 106-121 in Techniques and Procedures in Animal Production Research. A. B. Chapman, ed. American Society of Animal Production, Albany, NY.

Choudhary, E., B. A. Costine, M. E. Wilson, E. K. Inskeep, and J. A. Flores. 2004. Prostaglandin $\mathrm{F}_{2} \alpha\left(\mathrm{PGF}_{2} \alpha\right)$ independent and dependent regulation of the bovine luteal endothelin system. Domest Anim Endocrinol 27: 63-79.

Choudhary, E., A. Sen, E. K. Inskeep, and J. A. Flores. 2005. Developmental sensitivity of the bovine corpus luteum to prostaglandin $\mathrm{F}_{2} \alpha\left(\mathrm{PGF}_{2} \alpha\right)$ and endothelin-1 (ET1): Is ET-1 a mediator of the luteolytic actions of $\mathrm{PGF}_{2} \alpha$ or a tonic inhibitor of progesterone secretion? Biol Reprod 72: 633-642.

Committee on Reproductive Nomenclature. 1972. Recommendations for standardizing bovine reproductive terms. Cornell Vet. 62: 216-237.

Costine, B. A. 2004. Mechanisms of reduced luteal sensitivity to $\mathrm{PGF}_{2} \alpha$ in ruminants. PhD Diss. West Virginia University, Morgantown, WV, USA. pp. 61.

Costine, B. A., E. K. Inskeep, K. P. Blemings, J. A. Flores, and M. E. Wilson. 2007. Mechanisms of reduced luteal sensitivity to prostaglandin $\mathrm{F}_{2} \alpha$ during maternal recognition of pregnancy in ewes. Domest Anim Endocrinol 32: 106-121.

Crosier, A. E., P. W. Farin, M. J. Dykstra, J. E. Alexander, and C. E. Farin. 2001. Ultrastructural morphometry of bovine blastocysts produced in vivo or in vitro. Biol Reprod 64: 1375-1385.

Curran, S., R. A. Pierson, and O. J. Ginther. 1986a. Ultrasonographic appearance of the bovine conceptus from days 10 through 20. J Am Vet Med Assoc 189: 12891294.

Curran, S., R. A. Pierson, and O. J. Ginther. 1986b. Ultrasonographic appearance of the bovine conceptus from days 20 through 60. J Am Vet Med Assoc 189: 12951302. 
Dailey, R. A., E. K. Inskeep, and P. E. Lewis. 2002. Pregnancy failures in cattle: A prespective on embryo loss. Pages 1-8 in XVIIIth The international conference on reproduction of farm animals. University of Nitra, Nitra, Slovak Republic.

De Vries, A. 2006. Economic value of pregnancy in dairy cattle. J. Dairy Sci. 89: 38763885 .

De Vries, A., J. Van Leeuwen, and W. W. Thatcher. 2005. Economics of improved reproductive performance in dairy cattle. University of Florida, Institute of Food and Agricultural Sciences Extension Publication. Electronic Data Information Source: $\underline{\text { htp}: / / e d i s . i f a s . u f l . e d u / . ~}$

Dejarnette, J. M. 2005. The effect of semen quality on reproductive efficiency. Vet Clin North Am Food Anim Pract 21: 409-418.

Dennis, S. M. 1969. Laboratory diagnosis of infectious bovine abortion. J Am Vet Med Assoc 155: 1913-1922.

Downs, K. M. 1998. The murine allantois. Curr Top Dev Biol 39: 1-33.

Downs, K. M., and R. L. Gardner. 1995. An investigation into early placental ontogeny: Allantoic attachment to the chorion is selective and developmentally regulated. Development 121: 407-416.

Downs, K. M., and C. Harmann. 1997. Developmental potency of the murine allantois. Development 124: 2769-2780.

Downs, K. M., E. R. Hellman, J. McHugh, K. Barrickman, and K. E. Inman. 2004. Investigation into a role for the primitive streak in development of the murine allantois. Development 131: 37-55.

Dunwoodie, S. L., and R. S. Beddington. 2002. The expression of the imprinted gene IPL is restricted to extra-embryonic tissues and embryonic lateral mesoderm during early mouse development. Int J Dev Biol 46: 459-466.

Ellington, S. K. 1987. A morphological study of the development of the chorion of rat embryos. J Anat 150: 247-263. 
Erb, R. E., and E. W. Holtz. 1958. Factors associated with estimated fertilization and service efficiency of cows. Journal of Dairy Science 41: 1541-1552.

Farin, P. W., A. E. Crosier, and C. E. Farin. 2001. Influence of in vitro systems on embryo survival and fetal development in cattle. Theriogenology 55: 151-170.

Ferguson, J. D. 2005. Nutrition and reproduction in dairy herds. Vet Clin North Am Food Anim Pract 21: 325-347.

Flechon, J. E., and J. P. Renard. 1978. A scanning electron microscope study of the hatching of bovine blastocysts in vitro. J Reprod Fertil 53: 9-12.

Fogwell, R. L., C. W. Weems, G. S. Lewis, R. L. Butcher and E. K. Inskeep. 1978. Secretion of steroids after induced luteal regression in beef heifers: effects of $\mathrm{PGF}_{2} \alpha$ and removal of corpora lutea. J Anim Sci. 46:1718-1723.

French, P. D., and R. L. Nebel. 2003. The simulated economic cost of extended calving intervals in dairy herds and comparison of reproductive management programs. J Dairy Sci Suppl. 1: 54.

Fricke, P. M., and M. C. Wiltbank. 1999. Effect of milk production on the incidence of double ovulation in dairy cows. Theriogenology 52: 1133-1143.

Garrett, J. E., R. D. Geisert, M. T. Zavy and G. L. Morgan. 1988. Evidence for maternal regulation of early conceptus growth and development in beef cattle. J Reprod Fert. 84:437-446.

Girsh, E., Y. Greber, and R. Meidan. 1995. Luteotrophic and luteolytic interactions between bovine small and large luteal-like cells and endothelial cells. Biol Reprod 52: 954-962.

Girsh, E., R. A. Milvae, W. Wang, and R. Meidan. 1996a. Effect of endothelin-1 on bovine luteal cell function: Role in prostaglandin $\mathrm{F}_{2} \alpha$-induced antisteroidogenic action. Endocrinology 137: 1306-1312.

Girsh, E., W. Wang, R. Mamluk, F. Arditi, A. Friedman, R. A. Milvae, and R. Meidan. 1996b. Regulation of endothelin-1 expression in the bovine corpus luteum: Elevation by prostaglandin $\mathrm{F}_{2} \alpha$. Endocrinology 137: 5191-5196. 
Gomes, W. R., V. L. Estergreen, O. L. Frost, and R. E. Erb. 1963. Progestin levels in jugular and ovarian venous blood, corpora lutea, and ovaries of the nonpregnant bovine. Journal of Dairy Science 46: 553-558.

Greenstein, J. S., R. W. Murray, and R. C. Foley. 1958. Observations on the morphogenesis and histochemistry of the bovine preattachment placenta between 16 and 33 days of gestation. Anat Rec 132: 321-341.

Grimard, B., S. Freret, A. Chevallier, A. Pinto, C. Ponsart, and P. Humblot. 2006. Genetic and environmental factors influencing first service conception rate and late embryonic/foetal mortality in low fertility dairy herds. Anim Reprod Sci 91: $31-44$.

Gurtner, G. C., V. Davis, H. Li, M. J. McCoy, A. Sharpe, and M. I. Cybulsky. 1995. Targeted disruption of the murine VCAM1 gene: Essential role of VCAM1 in chorioallantoic fusion and placentation. Genes Dev 9: 1-14.

Guthrie, H. D., C. E. Rexroad, Jr., and D. J. Bolt. 1979. In vitro release of progesterone and prostaglandins $\mathrm{F}$ and $\mathrm{E}$ by porcine luteal and endometrial tissue during induced luteolysis. Adv Exp Med Biol 112: 627-632.

Hansen, P. J., and J. Block. 2004. Towards an embryocentric world: The current and potential uses of embryo technologies in dairy production. Reprod Fertil Dev 16: $1-14$.

Hasler, J. F. 2000. In vitro culture of bovine embryos in Menezo's B2 medium with or without coculture and serum: The normalcy of pregnancies and calves resulting from transferred embryos. Anim Reprod Sci 60-61: 81-91.

Hayashi, K., T. J. Acosta, B. Berisha, S. Kobayashi, M. Ohtani, D. Schams, and A. Miyamoto. 2003. Changes in prostaglandin secretion by the regressing bovine corpus luteum. Prostaglandins Other Lipid Mediat 70: 339-349.

Hill, J. R., R. C. Burghardt, K. Jones, C. R. Long, C. R. Looney, T. Shin, T. E. Spencer, J. A. Thompson, Q. A. Winger, and M. E. Westhusin. 2000. Evidence for placental abnormality as the major cause of mortality in first-trimester somatic cell cloned bovine fetuses. Biol Reprod 63: 1787-1794.

Hinckley, S. T., and R. A. Milvae. 2001. Endothelin-1 mediates prostaglandin $F_{2} \alpha-$ induced luteal regression in the ewe. Biol Reprod 64: 1619-1623. 
Humblot, P. 2001. Use of pregnancy specific proteins and progesterone assays to monitor pregnancy and determine the timing, frequencies and sources of embryonic mortality in ruminants. Theriogenology 56: 1417-1433.

Imwalle, D. B., D. L. Fernandez, and K. K. Schillo. 2002. Melengestrol acetate blocks the preovulatory surge of luteinizing hormone, the expression of behavioral estrus, and ovulation in beef heifers. J. Anim Sci. 80: 1280-1284.

Inskeep, E. K. 2004. Preovulatory, postovulatory, and postmaternal recognition effects of concentrations of progesterone on embryonic survival in the cow. J Anim Sci 82 E-Suppl: E24-39.

Inskeep, E. K., and R. A. Dailey. 2005. Embryonic death in cattle. Vet Clin North Am Food Anim Pract 21: 437-461.

Kastelic, J. P., S. Curran, and O. J. Ginther. 1989. Accuracy of ultrasonography for pregnancy diagnosis on days 10 to 22 in heifers. Theriogenology 31: 813-820.

Kastelic, J. P., D. L. Northey, and O. J. Ginther. 1991. Spontaneous embryonic death on days 20 to 40 in heifers. Theriogenology 35: 351-363.

Kato, Y., T. Tani, Y. Sotomaru, K. Kurokawa, J. Kato, H. Doguchi, H. Yasue, and Y. Tsunoda. 1998. Eight calves cloned from somatic cells of a single adult. Science 282: 2095-2098.

Kaufman, M. H. 1995. Pages 26-34 in The atlas of mouse development. Academic Press Inc. New York, NY.

Kinder, J. E., F. N. Kojima, E. G. Bergfeld, M. E. Wehrman, and K. E. Fike. 1996. Progestin and estrogen regulation of pulsatile LH release and development of persistent ovarian follicles in cattle. J Anim Sci 74: 1424-1440.

Kiyma, Z., B. M. Alexander, E. A. Van Kirk, W. J. Murdoch, D. M. Hallford, and G. E. Moss. 2004. Effects of feed restriction on reproductive and metabolic hormones in ewes. J Anim Sci 82:2548-2557.

Kolour, A. K., R. A. Batavani, and F. F. Ardabili. 2005. Preliminary observations on the effect of parity on first day ultrasonic detection of embryo and its organs in bovine. J Vet Med A Physiol Pathol Clin Med 52: 74-77. 
Kummerfeld, H. L., E. A. Oltenacu, and R. H. Foote. 1978. Embryonic mortality in dairy cows estimated by nonreturns to service, estrus, and cyclic milk progesterone patterns. J Dairy Sci 61: 1773-1777.

Lawson, R. A. S., and L. P. Cahill. 1983. modification of embryo-maternal relationship in ewes by progesterone treatment early in the estrous cycle. J Reprod Fert. 67:473475.

Ledgard, A. M., R. S. Lee, and A. J. Peterson. 2006. Expression of genes associated with allantois emergence in ovine and bovine conceptuses. Mol Reprod Dev 73: 10841093.

Lemley, C. O., J. M. Koch, and M. E. Wilson. 2007. Determination of insulin concentrations in sheep isocalorically supplemented with two different volatile fatty acids. J Anim Sci. Midwest Section Abst. 248.

Lopez, H., R. Sartori, and M. C. Wiltbank. 2005. Reproductive hormones and follicular growth during development of one or multiple dominant follicles in cattle. Biol Reprod 72: 788-795.

Lopez, H., L. D. Satter, and M. C. Wiltbank. 2004. Relationship between level of milk production and estrous behavior of lactating dairy cows. Anim Reprod Sci 81: 209-223.

Lucy, M. C. 2003. Mechanisms linking nutrition and reproduction in postpartum cows. Reprod Suppl 61: 415-427.

Maddox-Hyttel, P., N. I. Alexopoulos, G. Vajta, I. Lewis, P. Rogers, L. Cann, H. Callesen, P. Tveden-Nyborg, and A. Trounson. 2003. Immunohistochemical and ultrastructural characterization of the initial post-hatching development of bovine embryos. Reproduction 125: 607-623.

Mann, G. E., M. D. Fray and G. E. Lamming. 2006. Effects of time of progesterone supplementation on embryo development and interferon- $\tau$ production in the cow. Vet J. 171:500-3.

Mann, G. E. and G. E. Lamming. 2006. Timing of prostaglandin $F_{2} \alpha$ release episodes and oxytocin receptor development during luteolysis in the cow. Anim Reprod Sci. 93:328-36 
Maurer, R. R., and J. R. Chenault. 1983. Fertilization failure and embryonic mortality in parous and nonparous beef cattle. J Anim Sci 56: 1186-1189.

Meidan, R., and N. Levy. 2002. Endothelin-1 receptors and biosynthesis in the corpus luteum: Molecular and physiological implications. Domest Anim Endocrinol 23: 287-298.

Milvae, R. A., and W. Hansel. 1980. The effects of prostacyclin $\left(\mathrm{PGI}_{2}\right)$ and 6-keto-PGF $1 \alpha$ on bovine plasma progesterone and LH concentrations. Prostaglandins 20: 641647.

Milvae, R. A., and W. Hansel. 1983. Prostacyclin, prostaglandin $\mathrm{F}_{2} \alpha$ and progesterone production by bovine luteal cells during the estrous cycle. Biol Reprod 29: 10631068.

Milvae, R. A., H. W. Alila, and W. Hansel. 1986. Involvement of lipoxygenase products of arachidonic acid metabolism in bovine luteal function. Biol Reprod 35: 12101215.

Parr, R. A., I. F. Davis, M. A. Miles, and T. J. Squires. 1993. Liver blood flow and metabolic clearance rate of progesterone in sheep. Res Vet Sci 55: 311-316.

Patek, C. E., and J. Watson. 1976. Prostaglandin F and progesterone secretion by porcine endometrium and corpus luteum in vitro. Prostaglandins 12: 97-111.

Perry, G. A., M. F. Smith, M. C. Lucy, J. A. Green, T. E. Parks, M. D. MacNeil, A. J. Roberts, and T. W. Geary. 2005. Relationship between follicle size at insemination and pregnancy success. Proc Natl Acad Sci USA 102: 5268-5273.

Piedrahita, J. A., D. N. Wells, A. L. Miller, J. E. Oliver, M. C. Berg, A. J. Peterson, and H. R. Tervit. 2002. Effects of follicular size of cytoplast donor on the efficiency of cloning in cattle. Molecular Reproduction and Development 61: 317-326.

Pierson, R. A., and O. J. Ginther. 1984. Ultrasonography for detection of pregnancy and study of embryonic development in heifers. Theriogenology 22: 225-233.

Plaizier, J. C., G. J. King, J. C. Dekkers, and K. Lissemore. 1997. Estimation of economic values of indices for reproductive performance in dairy herds using computer simulation. J Dairy Sci 80: 2775-2783. 
Poelmann, R. E. 1981. The head-process and the formation of the definitive endoderm in the mouse embryo. Anat Embryol (Berl) 162: 41-49.

Rabiee, A. R., K. L. Macmillan, and F. Schwarzenberger. 2001a. The effect of level of feed intake on progesterone clearance rate by measuring faecal progesterone metabolites in grazing dairy cows. Anim Reprod Sci 67: 205-214.

Rabiee, A. R., K. L. Macmillan, and F. Schwarzenberger. 2001b. Excretion rate of progesterone in milk and faeces in lactating dairy cows with two levels of milk yield. Reprod Nutr Dev 41: 309-319.

Rabiee, A. R., K. L. Macmillan, and F. Schwarzenberger. 2001c. Progesterone metabolism in ovariectomised non-lactating holstein-friesian cows treated with progesterone with two levels of feed intake. Anim Reprod Sci 66: 35-46.

Rabiee, A. R., D. Dalley, J. M. Borman, K. L. Macmillan, and F. Schwarzenberger. 2002a. Progesterone clearance rate in lactating dairy cows with two levels of dry matter and metabolisable energy intakes. Anim Reprod Sci 72: 11-25.

Rabiee, A. R., K. L. Macmillan, and F. Schwarzenberger. 2002b. Plasma, milk and faecal progesterone concentrations during the oestrous cycle of lactating dairy cows with different milk yields. Anim Reprod Sci 74: 121-131.

Rabiee, A. R., K. L. Macmillan, F. Schwarzenberger, and P. J. Wright. 2002c. Effects of level of feeding and progesterone dose on plasma and faecal progesterone in ovariectomised cows. Anim Reprod Sci 73: 185-195.

Revah, I., and W. R. Butler. 1996. Prolonged dominance of follicles and reduced viability of bovine oocytes. J Reprod Fertil 106: 39-47.

Rexroad, C. E., Jr., and H. D. Guthrie. 1979. Prostaglandin $\mathrm{F}_{2} \alpha$ and progesterone release in vitro by ovine luteal tissue during induced luteolysis. Adv Exp Med Biol 112: 639-644.

Roberts, R. M., and F. W. Bazer. 1988. The functions of uterine secretions. J Reprod Fertil 82: 875-892. 
Sangsritavong, S., D. K. Combs, R. Sartori, L. E. Armentano, and M. C. Wiltbank. 2002. High feed intake increases liver blood flow and metabolism of progesterone and estradiol-17ß in dairy cattle. J Dairy Sci $85: 2831-2842$.

Santos, J. E., W. W. Thatcher, R. C. Chebel, R. L. Cerri, and K. N. Galvao. 2004. The effect of embryonic death rates in cattle on the efficacy of estrus synchronization programs. Anim Reprod Sci 82-83: 513-535.

Sartori, R., J. M. Haughian, R. D. Shaver, G. J. M. Rosa, and M. C. Wiltbank. 2004. Comparison of ovarian function and circulating steroids in estrous cycles of holstein heifers and lactating cows. J. Dairy Sci. 87: 905-920.

Satterfield, M. C., F. W. Bazer, and T. E. Spencer. 2006. Progesterone regulation of preimplantation conceptus growth and galectin 15 (GALS15) in the ovine uterus. Biol Reprod 75: 289-296.

Sen, A., E. Choudhary, E. K. Inskeep, and J. A. Flores. 2005. Effects of selective protein kinase $\mathrm{C}$ isozymes in prostaglandin $\mathrm{F}_{2} \alpha$-induced $\mathrm{Ca}^{2+}$ signaling and luteinizing hormone-induced progesterone accumulation in the mid-phase bovine corpus luteum. Biology of Reproduction 72: 976-984.

Sen, A., M. Wright, E. K. Inskeep, and J. A. Flores. 2006. Participation of specific PKC isozymes in the inhibitory effect of ET-1 on progesterone accumulation in cells isolated from early- and mid-phase corpora lutea. Domest Anim Endocrinol 31: 284-299.

Shapiro, S. S., and M. B. Wilk. 1965. An analysis of variance for normality (complete samples). Biometrika 52: 591-611.

Sheffel, C. E., B. R. Pratt, W. L. Ferrell, and E. K. Inskeep. 1982. Induced corpora lutea in the postpartum beef cow. Ii. Effects of treatment with progestogen and gonadotropins. J Anim Sci 54: 830-836.

Shemesh, M., and W. Hansel. 1975. Stimulation of prostaglandin synthesis in bovine ovarian tissues by arachidonic acid and luteinizing hormone. Biol Reprod 13: 448-452.

Smith, M. W., and J. S. Stevenson. 1995. Fate of the dominant follicle, embryonal survival, and pregnancy rates in dairy cattle treated with prostaglandin $F_{2} \alpha$ and 
progestins in the absence or presence of a functional corpus luteum. J Anim Sci. 73: 3743-3751.

Smith, D. L., B. M. Stinefelt, K. P. Blemings, and M. E. Wilson. 2006. Diet-induced alterations in progesterone clearance appear to be mediated by insulin signaling in hepatocytes. J Anim Sci 84:1102-1109.

Sreenan, J. M., and M. G. Diskin. 1983. Early embryonic mortality in the cow: Its relationship with progesterone concentration. Vet Rec 112: 517-521.

Sreenan, J. M., and M. G. Diskin. 1986. The extent and timing of embryonic mortality in the cow. Pages 1-9 in Embryonic Mortality in Farm Animals. J. M. Sreenan and M. G. Diskin eds. Dordrecht: Martinus Nijhoff Publishers.

Starbuck, M. J., R. A. Dailey, and E. K. Inskeep. 2004. Factors affecting retention of early pregnancy in dairy cattle. Anim Reprod Sci 84: 27-39.

Stevenson, J. S. 2001. Reproductive management of dairy cows in high milk-producing herds. Journal of Dairy Science 84: E128-E143

Stock, A. E., and J. E. Fortune. 1993. Ovarian follicular dominance in cattle: Relationship between prolonged growth of the ovulatory follicle and endocrine parameters. Endocrinology 132: 1108-1114.

Stormshak, F., E. K. Inskeep, J. E. Lynn, A. L. Pope, and L. E. Casida. 1963. Progesterone levels in corpora lutea and ovarian effluent blood of the ewe. J Anim Sci 22: 1021-1026.

Taft, R., N. Ahmad, and E. K. Inskeep. 1996. Exogenous pulses of luteinizing hormone cause persistence of the largest bovine ovarian follicle. J Anim Sci 74: 2985-2991.

Tanabe, T. Y., and L. E. Casida. 1949. The nature of reproductive failures in cows of low fertility. J Dairy Sci 32: 273.

Thomas, D. L., P. J. Thomford, J. G. Crickman, A. R. Cobb, and P. J. Dziuk. 1987. Effects of plane of nutrition and phenobabrbital during the pre-mating period on reproduction in ewes fed differentially during the summer and mated in the fall. $J$ Anim Sci. 64: 1144-1152. 
Tsai, S. J., and M. C. Wiltbank. 1997. Prostaglandin $F_{2} \alpha$ induces expression of prostaglandin $\mathrm{G} / \mathrm{H}$ synthase-2 in the ovine corpus luteum: A potential positive feedback loop during luteolysis. Biol Reprod 57: 1016-1022.

Tsai, S. J., and M. C. Wiltbank. 1998. Prostaglandin $F_{2} \alpha$ regulates distinct physiological changes in early and mid-cycle bovine corpora lutea. Biol Reprod 58: 346-352.

Ushizawa, K., C. B. Herath, K. Kaneyama, S. Shiojima, A. Hirasawa, T. Takahashi, K. Imai, K. Ochiai, T. Tokunaga, Y. Tsunoda, G. Tsujimoto, and K. Hashizume. 2004. cDNA microarray analysis of bovine embryo gene expression profiles during the pre-implantation period. Reprod Biol Endocrinol 2: 77.

Vasconcelos, J. L., S. Sangsritavong, S. J. Tsai, and M. C. Wiltbank. 2003. Acute reduction in serum progesterone concentrations after feed intake in dairy cows. Theriogenology 60: 795-807.

Villa-Godoy, A., T. L. Hughes, R. S. Emery, L. T. Chapin, and R. L. Fogwell. 1988. Association between energy balance and luteal function in lactating dairy cows. J Dairy Sci 71: 1063-1072.

Vincent, D. L., S. Meradith and E. K. Inskeep. 1986. Advancement of uterine secretion of prostaglandin $\mathrm{E}_{2}$ by treatment with progesterone and transfer of asynchronous embryos. Endocrinology. 119:527-529.

Wade, D. E., and G. S. Lewis. 1996. Exogenous prostaglandin $F_{2} \alpha$ stimulates uteroovarian release of prostaglandin $\mathrm{F}_{2} \alpha$ in sheep: A possible component of the luteolytic mechanism of action of exogenous prostaglandin $\mathrm{F}_{2} \alpha$. Domest Anim Endocrinol 13: 383-398.

Watson, J., and C. E. Patek. 1979. Steroid and prostaglandin secretion by the corpus luteum, endometrium and embryos of cyclic and pregnant pigs. J Endocrinol 82: 425-428.

Weersink, A., J. A. VanLeeuwen, J. Chi, and G. P. Keefe. 2002. Direct production losses and treatment costs due to four dairy cattle diseases. Proc. Western Canadian Dairy Seminar, Red Deer, Alberta, Canada. Adv. Dairy Technol. 14: 55-75.

Wiltbank, M., H. Lopez, R. Sartori, S. Sangsritavong, and A. Gumen. 2006. Changes in reproductive physiology of lactating dairy cows due to elevated steroid metabolism. Theriogenology 65: 17-29. 